\title{
Régimen jurídico de las edificaciones en situación de asimilación a fuera de ordenación
}

\section{Alberto Pardo Moreno}

\begin{abstract}
Abogado
I. INTRODUGCIÓN: 1. Potestad de disciplina urbanística: A. Definición. B. Evolución histórica. 2. Concepto de situación legal de fuera de ordenación. 3. Definición de "asimilación" a fuera de ordenación. 4. Bases constitucionales. 5. Distribución de competencias. II. REGULACIÓN ESTATAL. III. REGULACIÓN ANDALUZA: 1. El régimen de fuera de ordenación en la LOUA: A. Concepto y clases de la situación de fuera de ordenación. B. Actuaciones urbanísticas autorizables en edificios de fuera de ordenación. C. Complemento normativo de la regulación jurídica de fuera de ordenación. 2. La declaración en situación de "asimilación" a la de fuera de ordenación del RDUA: A. Operatividad del nuevo plazo de prescripción de seis años introducido por la Ley 2/2012, de 30 de enero, que modifica el art. 185.1 de la LOUA. B. Del cumplimiento por equivalencia. C. Necesario reflejo registral de las limitaciones del régimen de asimilado a fuera de ordenación. 3. Adaptación de la LOUA al RDUA. 4. Decreto andaluz 2/2012 sobre regulación del régimen de las edificaciones y asentamientos existentes en suelo no urbanizable. A. Soluciones abordadas para las edificaciones existentes en el suelo no urbanizable. a). Del "efecto directo horizontal" de las Directivas medioambientales. b). Importancia del art. 8.2 del Decreto. B. Procedimiento general de declaración de situación de asimilación a fuera de ordenación. C. De la reclasificación de los suelos como última solución. IV. CONGLUSIONES. BIBLIOGRAFÍA.
\end{abstract}

\section{RESUMEN:}

En este estudio hemos intentado analizar los aspectos más relevantes de la regulación jurídica de la "situación de asimilación a fuera de ordenación", cuyo origen jurisprudencial desembocó, a través del Reglamento de Disciplina Urbanística de Andalucía (en adelante RDUA), en su reflejo como norma de Derecho positivo. Tradicionalmente, nuestro derecho urbanístico ha padecido una situación patológica de indisciplina urbanística, sobre todo en el ámbito del suelo no urbanizable, provocando profundos daños, en ocasiones irreparables. Esta circunstancia, unida a la especial preocupación del Gobierno andaluz en buscar soluciones útiles a la práctica diaria, según reconoce el propio RDUA en su Exposición de motivos, justifica esta nueva figura jurídica. Así, se profundiza en la regulación jurídica que de la situación 
de asimilación a fuera de ordenación realiza el RDUA a través de su artículo 53, intentando desbrozar los dos posibles supuestos de hecho para declarar AFO, bien por el transcurso del plazo para restablecer la legalidad urbanística, bien por el llamado "cumplimiento por equivalencia". A renglón seguido, hacemos hincapié en la adaptación que la Ley 7/2002, de Ordenación Urbanística de Andalucía, realiza de esta figura fruto de su modificación por la Ley 2/2012, para concluir con la importante regulación jurídica que del régimen de las edificaciones y asentamientos existentes en suelo no urbanizable en la Comunidad Autónoma de Andalucía realiza el Decreto 2/2012, de 10 de enero, profundizando en la problemática suscitada por las dudas de que existan ciertas categorías de suelo de especial protección en municipios sin planeamiento y en la posibilidad de poder apreciar AFOs en aquellas edificaciones ubicadas en asentamientos urbanísticos.

\section{PALABRAS GLAVES:}

Asimilación a fuera de ordenación; cumplimiento por equivalencia; Reglamento de Disciplina Urbanística de Andalucía; suelo no urbanizable y legalidad urbanística.

\section{ABSTRACT:}

"In this study we have attempted to analyze the most relevant aspects of the legal regulation of the "situación de asimilado al régimen de fuera de ordenación" (asimilated to out of regulation status) whose jurisprudential origin led through the Regulation of Urban Discipline of Andalucía (hereinafter RDUA) in his reflection as rule of positive law. Traditionally, our Town Planning Law has suffered a pathological situation of urban indiscipline, especially in the country areas, causing extensive damage, sometimes irreparable. This, coupled with the concern of the Andalusian Government to seek practical solutions to everyday practice, as acknowledged by the RDUA's Introduction, justifies this new legal form. So, we deepens into the legal regulation of the status of assimilation exposed into the section 53 RDUA, trying to clear the two possible factual paths to state an AFOs (out or regulation areas): thus, by the passing of time in order to restore the legality of the Town planning, either by the so-called "compliance equivalence". Immediately afterwards, we emphasize the adaptation that Act 7/2002 of Town Planning of Andalusia makes in this subject, as a result of its amendment by Act 2/2012. Finally, we conclude with the study of the important legal regulatory regime of buildings and existing settlements in country areas made in in Andalucia by Decree 2/2012, of 10th January, deepening the problems raised by the doubts that exist certain categories of protected land in municipalities without town planning and the possibility of declaring AFOs in certain buildings located in urban settlements".

\section{KEY WORDS:}

Asimilated to out of regulation status; compliance equivalence; Regulation of Urban Discipline of Andalucía; country áreas and legality of the town planning. 


\section{INTRODUGCIÓN}

\section{Potestad de disciplina urbanística.}

En el urbanismo confluyen una gran cantidad de intereses; intereses que si no están correctamente tutelados llevarían a la pérdida del sistema del Derecho Urbanístico.

Pues bien, para evitar el divorcio entre la legalidad urbanística y la realidad existente en multitud de casos, se atribuyen una serie de potestades a la Administración que, tomando como base los deberes, límites o prohibiciones que marca el Derecho Urbanístico, establecen los medios necesarios para garantizar, por un lado, el cumplimiento de la legalidad urbanística y, de otro, reaccionar ante los casos de incumplimiento.

A esta potestad la conocemos como la potestad de Disciplina Urbanística ${ }^{1}$.

\section{A. Definición.}

Centrándonos preferentemente, durante el desarrollo de este artículo, en la normativa aplicable en la Comunidad Autónoma Andaluza, la Ley 7/2002, de 17 de diciembre, de Ordenación Urbanística de Andalucía (LOUA), se dedica un título completo (Título VI) determinando las potestades administrativas que comporta.

Así, podemos definir la Disciplina Urbanística, según lo previsto en los arts. 2 y 168 de la LOUA, como el ejercicio de potestades administrativas dirigidas a asegurar el cumplimiento de la legislación y ordenación urbanísticas. A efectos del art. 168 de la LOUA, se describe como una potestad administrativa aparejada de una actividad ejecutiva que nos resalta el carácter intervencionista en materia de urbanismo y ordenación del territorio, donde debemos destacar, entre las potestades más significativas, la intervención preventiva de los actos de edificación o construcción y uso del suelo; la inspección urbanística de la ejecución de los actos sujetos a dicha intervención; la protección de la legalidad urbanística y el restablecimiento del orden jurídico perturbado.

${ }^{1}$ Con carácter general, véase Luciano PAREJO ALFONSO, La disciplina urbanística, Madrid, Iustel, 2006, y el volumen de actas del III Congreso de la Asociación Española de Profesores de Derecho Administrativo, El control de la legalidad urbanística. 
De este modo, la Disciplina Urbanística cabe resumirse como el sistema de "control" que la Administración Pública, especialmente la municipal, ejerce sobre los actos de los administrados desplegado en diferentes vertientes. Entre ellos están:

El "control preventivo", consistente en el sometimiento de ciertos actos a la previa y preceptiva licencia municipal (STS de 9 de octubre de 1998). El "control a posteriori”, debiendo efectivo cumplimiento de los deberes urbanísticos impuestos por la Administración municipal una vez realizada la obra. El "control frente a situaciones legalizables", con la consiguiente protección de la legalidad urbanística y El "control por incumplimiento de la legalidad", justificadora de la potestad sancionadora de las Administraciones Públicas.

\section{B. Evolución histórica.}

Tradicionalmente, una de las grandes lacras de nuestro urbanismo ha sido que reinaba, como regla general, una indisciplina urbanística manifiesta2. Ya la Ley del Suelo de 1956 y su reforma de 1975, manifestaron esta deficiencia justificada por motivos de precariedad de instrumentos preventivos, represivos y correctores de que disponía la Administración. Motivos como la resistencia por parte de los propietarios, la falta de medios técnicos de los municipios y la desorganización existente en la propia Administración central, provocaron la poca exitosa aplicación práctica de esta Ley. Junto a estos motivos, y en opinión de LÓPEZ RAMÓN ${ }^{3}$, también resalta la falta de planeamiento general (ya que la Ley hizo descansar todas las técnicas sobre la base de los planes pero al ser estos escasos y tardíos, el mecanismo acabo resintiéndose), el contexto político, la debilidad estructural administrativa y la escasa preparación de los agentes a la hora de poner en marcha el dispositivo legal.

${ }^{2}$ Sobre la evolución del urbanismo español a partir del siglo XIX resultan recomendables los siguientes estudios: del administrativista Martín BASSOLS COMA, Génesis y evolución del Derecho Urbanístico Español, Madrid, 1973, pionero en esta materia; completando el anterior, Luciano PAREJO ALFONSO, La ordenación urbanística, Madrid, 1979. Una monografía que ofrece una gran síntesis sobre la evolución de los contenidos del planeamiento urbanístico español es la del arquitecto e historiador del urbanismo, Fernando DE TERÁN, Planeamiento urbano en la España contemporánea, Madrid, 1982.

${ }^{3}$ En relación a la crisis técnica del urbanismo español y el urbanismo sostenible, puede encontrarse en Fernando LÓPEZ RAMÓN, "Crisis y renovación del urbanismo español en la última década del siglo XX”, en Revista Española de Derecho Administrativo, núm. 104, 1999. 
Es en este contexto, caracterizado por una situación patológica de indisciplina urbanística existente sobre todo en el suelo no urbanizable, por lo que la legislación urbanística ve necesaria la aplicación de técnicas encaminadas a la Protección de la Legalidad Urbanística y justificativa de la represión de aquellas conductas que infrinjan esa legalidad.

Así, tras la reforma de la Ley del Suelo de 1975, se reacciona contra la realidad normativa anterior y, con el propósito de depurar las actuaciones urbanísticas irregulares, se estableció un cuadro de medidas al respecto.

Entre ellas, RAMÓN FERNANDEZ considera necesario hacer una distinción entre las siguientes:

1.-En relación a las adoptadas respecto a las "Obras sin o contra licencia", la principal diferencia con la normativa anterior, estriba en que la acción de la Administración no se limita al período de ejecución de la obra, sino que se extiende en el tiempo durante el año siguiente a la terminación total de la misma (art. 185.1 TR 76).

Plazo que el TR de 1992 en su art. 249 extendió a cuatro años y actualmente fijado por la LOUA en su art. 185.1 en seis años (según modificación aprobada por el Pleno del Parlamento de Andalucía en sesión celebrada el día 25 de enero de 2012).

2.-En cuanto a las "Obras realizadas al amparo de licencias ilegales", exige como presupuesto de hecho que la infracción sea calificada como grave o muy grave.

Si las obras están "en curso", la Ley resuelve con absoluta limpieza y corrección técnica porque asegura que los hechos no lleguen a consumarse definitivamente gracias a la paralización inmediata de la obra y garantiza los posibles errores o abusos de la Administración al remitir la decisión definitiva a los Tribunales de Jurisdicción Contencioso-Administrativos.

Si la obra ya está "consumada" por haberse terminado, la Administración podrá revisar de oficio la licencia de aquellos actos declarados nulos de pleno derecho según la reforma de la Ley de Procedimiento Común por Ley 4/1999. Tras esta reforma, los actos no declarados nulos de pleno derecho solo son objeto de control a través del recurso de lesividad.

3.-En relación a las "Obras y licencias en zonas verdes y espacios libres", opera los mismos mecanismos anteriormente expuestos con la salvedad de que, al ser 
actos de especial protección por su calificación, no opera ni el límite temporal de seis años, ni límite temporal alguno para la revisión de oficio.

\section{Concepto de situación legal de fuera de ordenación.}

El atención al término de la institución de fuera de ordenación, conviene significar que su configuración, en nuestra cultura urbanística, ha sido fruto, por una parte, de los distintos pronunciamientos jurisprudenciales (STSJM de 21 de diciembre de 2007; SSTS de 24 de marzo de 1997 y de 11 de octubre de 2001; STSJC de 15 de febrero de 2010), sumado a su progresiva regulación en las distintas normas legales y reglamentarias autonómicas a raíz de su delimitación contemplada en el art. 48 de la Ley del Suelo de 1956, calificándola como "la figura que regula las edificaciones e instalaciones existentes con anterioridad a la vigencia del nuevo planeamiento, así como las industrias ubicadas en zonas cuya calificación resultase disconforme con el Planeamiento". Dicho contenido, extendido a lo largo de las posteriores regulaciones urbanísticas (art. 60 del TRLS de 1976; art. 137 del TRLS de 1992 y Ley del Suelo y Valoraciones de 1998), se centra en el propósito de que dichas edificaciones, que se encuentran en situación de disconformidad con los instrumentos de planeamiento, no prolonguen su existencia más allá del tiempo necesario para su desaparición ${ }^{4}$, bien por la consunción del mismo, bien por la eliminación física derivada de los efectos de las previsiones urbanísticas.

Así, debemos reseñar como notas características, la imposibilidad de que desaparezcan inmediatamente y la no permisividad de obras que consoliden y alarguen la vida útil de estas edificaciones desordenadas, siendo admitidas, única y exclusivamente, las obras de conservación o mantenimiento que sean precisas e imprescindibles para mantener el edificio en correctas condiciones de habitabilidad e higiene.

Fue, a raíz de la STC 61/1997, de 20 de marzo, cuando las distintas legislaciones urbanísticas autonómicas han ido configurando, sobre la base de una regulación jurídica del régimen de fuera de ordenación continuista con la legislación estatal desarrollada, un régimen jurídico más completo cuyo objetivo ha sido cubrir las lagunas jurídicas existentes y concretar multitud de supuestos de la legislación estatal supletoria.

${ }^{4}$ CABALLEIRA RIVERA, M ${ }^{a}$ Teresa, "Edificios fuera de ordenación y obras permitidas", Revista de Derecho urbanístico y Medio Ambiente, no 214, 2004, pág. 12. 
Así, y destacando la postura de CABALLEIRA RIVERA, se reconocen hasta tres tipos distintos de regulación normativa autonómica:

- Comunidades Autónomas que han configurado un específico régimen jurídico de fuera de ordenación en su legislación urbanística.

- Aquellas que desarrollan de manera exclusiva las pautas de actuación a seguir.

- Las que remiten su positivación normativa a los respectivos instrumentos de planeamiento urbanísticos.

Es a este tercer grupo, caracterizado por desarrollar la llamada "deslegalización" consagrada por el TRLS de 1992 (Art. 137.2), donde podemos adscribir la sistemática seguida por la Comunidad Autónoma de Andalucía respecto a la regulación jurídica del régimen de fuera de ordenación. Este supuesto de delegación normativa a favor de los instrumentos de planeamiento, convierte a la legislación normativa autonómica sobre el régimen de fuera de ordenación en supletorio, a expensas de ser aplicado en ausencia de un desarrollo normativo por dichos instrumentos de planeamiento urbanísticos.

Este régimen de autonomía local reconocido por la delegación permitida, en un Estado formado por más de ocho mil municipios, no sólo es limitativo del derecho de propiedad fruto de la atribución normativa asumida en el ámbito local, sino que es generadora de una fuente de conflictos derivando en una situación de inseguridad jurídica. Es por ello, que considero acertada la aportación de LÓPEZ PÉREZ, al manifestar la conveniencia de que sea el Plan General el que declare qué edificios deben quedar en situación de fuera de ordenación, favoreciendo en consecuencia la seguridad jurídica.

\section{Definición de "asimilación a fuera de ordenación".}

Estamos ante un concepto meramente jurisprudencial que no tuvo reflejo normativo hasta su inclusión en el Reglamento de Disciplina Urbanística de Andalucía, aprobado por Decreto 60/2010, de 16 de marzo.

Así, la jurisprudencia se planteó la cuestión de determinar en qué situación deberían quedar aquellas edificaciones o instalaciones que, a pesar de haber sido construidas de manera ilegal, había prescrito la posibilidad de su demolición. Ante el silencio de la Ley, la jurisprudencia, dando carta de naturaleza a estas situaciones, resolvió que quedarían en una situación "asimilada" al régimen legal de fuera de ordenación. En tal sentido, la STS de 5 de diciembre de 1987, recurso 1987/9365, estableció que: 
"En derecho urbanístico el transcurso de los plazos con los que la administración cuenta para proceder a la demolición de las obras realizadas sin licencia o excediéndose de la licencia otorgada consolida la obra ilegalmente construida... razón por la cual se aplica "analógicamente" el régimen de fuera de ordenación..."

Añadiendo la prohibición para:

"la realización de obras que pudieren alargar artificialmente la vida de la edificación, para no hacer de mejor condición a las obras nacidas de la ilegalidad que las hechas de acuerdo con la ordenación urbanística que luego devienen disconformes con ella."

En los mismos términos, se expresan las SSTS 4 de junio de 1994; 2 de noviembre de 1994; 6 de febrero, 19 de mayo y 6 de octubre de 1992; 6 de febrero de 1991.

Esta nueva figura jurídica, es desarrollada y recogida expresamente, confiriéndole carácter normativo a la doctrina consolidada, por el Reglamento de Disciplina Urbanística de Andalucía, la cual está ligada al ejercicio de la disciplina urbanística siendo su finalidad la preservación, en materia de urbanismo, de los intereses generales en conexión con el medio ambiente. Es la propia Exposición de Motivos del RDUA, la que se encarga de incluir entre sus propósitos, la aspiración de proporcionar soluciones útiles a la práctica diaria, a través de figuras como la "asimilación a fuera de ordenación" y el "cumplimiento por equivalencia".

Para definirla, y según opinión de GALLEGO ALCALÁ ${ }^{5}$, debemos partir de la base de que toda infracción de la normativa urbanística o vulneración de la legalidad urbanística, comporta, por parte de la Administración competente, el deber de iniciar un procedimiento de protección de la legalidad urbanística con el respectivo restablecimiento del orden jurídico perturbado y la incoación de un procedimiento administrativo sancionador.

No obstante, a veces, por un ánimo excesivamente recaudatorio, la Administración se limita a ejercitar el procedimiento administrativo sancionador, dejan-

${ }^{5} \mathrm{Al}$ respecto J. Domingo GALLEGO ALCALÁ, Breve aproximación al artículo 53 del Reglamento de Disciplina Urbanística de Andalucía, realiza una gran labor fruto de la necesidad de profundizar en esta figura de reciente configuración en el RDUA, la cual conlleva relevantes efectos en el quehacer diario de los operadores jurídicos y técnicos locales, así como de los profesionales del derecho, particularmente del siempre complejo y técnico Derecho Administrativo Urbanístico. 
do que transcurra el plazo de prescripción de la infracción urbanística contemplado en el artículo 185.1 de la LOUA. Al transcurrir dicho plazo de seis años, con base en la inactividad material de la Administración, y no ejecutada la potestad de restablecimiento de la legalidad, entra en juego el cuestionamiento del principio de seguridad jurídica.

Al plantearnos cuales serían las consecuencias o el futuro que albergaría este tipo de construcciones, edificaciones e instalaciones ilegales, debemos hacer referencia a diferentes posturas doctrinales adoptadas al respecto.

Una primera corriente doctrinal, avala la tesis de la "sanación" de la ilegalidad motivada por el mero transcurso del plazo de seis años anteriormente referido. Ello supondría adquirir facultades urbanísticas a la Administración "contra norma". En referencia a la Jurisprudencia del Tribunal Supremo en su sentencia de 28 de enero de 2009, determinó que:

"no se podían adquirir licencias por silencio administrativo en contra de la ordenación territorial o urbanística...".

Una segunda postura defiende que lo que es en origen ilegal, continua siéndolo. En tal caso perdería efecto la prescripción, ya que la Administración estaría siempre facultada para incoar el procedimiento de restablecimiento del orden jurídico perturbado incluso después del plazo máximo fijado por la norma.

Finalmente, el legislador andaluz adoptó una posición ecléctica, determinando que tales edificaciones, construcciones e instalaciones no serían ni legales ni ilegales, sino que estarían en "situación de asimilación a fuera de ordenación" operando los plazos de prescripción.

En este sentido, la jurisprudencia del TS en sentencia de 12 de junio de 2003, fija la siguiente doctrina legal:

"La declaración de caducidad y archivo de actuaciones establecidas para procedimientos en que la Administración ejercite potestades sancionadoras, artículo 44.2 de la Ley 30/92 (En los procedimientos en que la Administración ejercite potestades sancionadoras o, en general, de intervención, susceptibles de producir efectos desfavorables o de gravamen, se producirá la caducidad. En estos casos, la resolución que declare la caducidad ordenará el archivo de las actuaciones, con los efectos previstos en el artículo 92.), no extinguen la acción de la Administración para ejercitar las potestades aludidas en ese precepto, siéndoles plenamente aplicable el artículo 92.3 de la misma Ley". 
Es en este contexto de búsqueda inagotable de soluciones ante situaciones en las que tanto la acción penal como la administrativa han prescrito, donde aparece la figura del "asimilado a fuera de ordenación", definida como la situación referida a las construcciones clandestinas o ilegales desde el momento de su nacimiento, que han quedado inmunes a la acción de restablecimiento de la legalidad urbanística perturbada por el mero transcurso del tiempo.

\section{Bases constitucionales.}

Aunque la legislación urbanística responde a un tipo de legislación llamada de "procedimiento" por establecer principalmente requisitos, trámites y competencias para la aprobación de los instrumentos de planeamiento, también existen regulaciones sustantivas sobre el uso del suelo.

Por ello, es preceptivo hacer referencia a los objetivos constitucionales de los que trae causa el urbanismo. Entre esos diferentes objetivos, cabe subrayar el relativo a la protección del medio ambiente (art. $45 \mathrm{CE}$ ), a la protección del patrimonio cultural (art. $46 \mathrm{CE}$ ) y, como el más determinante desde el punto de vista de la ordenación urbanística, el de reconocimiento del derecho a una vivienda digna y adecuada (art. $47 \mathrm{CE})^{6}$.

La efectividad jurídica de tales preceptos viene a reforzarse desde el momento en que se indica que serán los poderes públicos los encargados de velar, proteger, garantizar, conservar y promover las condiciones necesarias para la consecución de la efectividad de tales derechos.

La doctrina dominante, entiende que tal grado de vinculación de los poderes públicos a los principios rectores de la política social y económica, entre los que están encuadrados estos preceptos, no pueden traducirse en unos mecanismos de protección idénticos a los utilizados para los Derechos Públicos Subjetivos Fundamentales.

No obstante, la única salvedad de tal diferencia procedimental se subsanaría, según se deriva del art. 53.3 CE, cuando dispone que para que estos derechos

\footnotetext{
${ }^{6}$ Destaquemos la singularidad de la Constitución española, cuando pone en relieve la importancia del urbanismo reconociendo su vinculación con la necesidad de dar habitación suficiente a la población en crecimiento. Es en este punto donde se marca el leit-motiv del reconocimiento constitucional de la legislación de ensanche. A su vez, este precepto, legitima la regulación de los usos del suelo acordes con el interés general, reforzando el art. $33 \mathrm{CE}$ el cual asigna a la función social la delimitación del contenido del derecho de propiedad.
} 
puedan ser residenciados ante la jurisdicción ordinaria deben disponerlo las leyes que los desarrollen. De ahí, que algunos autores califiquen estos derechos como Derechos Públicos Subjetivos no Fundamentales.

Ciertamente, es importante destacar que la puesta en práctica de este derecho subjetivo a disfrutar de una vivienda digna y adecuada, es cuanto menos difícil de llevar a cabo. Desde el punto de vista de la literalidad del derecho, sería necesario determinar el titular del derecho, el obligado para su efectividad y el objeto del mismo. Ello llevaría aparejado una serie de inconvenientes prácticos que conducirían a situaciones injustas e incluso violentas.

En todo caso, esta exigencia constitucional sí legitima al establecimiento de políticas activas públicas de viviendas ${ }^{7}$ como pueden ser la promoción pública de viviendas asequibles, las reservas de suelo para viviendas asequibles o arrendamientos forzosos de viviendas desocupada, etc....

Lo criticable del asunto es que el legislador no se ha preocupado de determinar la efectividad de estos derechos precisando el titular activo y pasivo del mismo y los términos de su aplicación, sino que se ha limitado a atribuir de forma genérica las características que ha de cumplir la vivienda para alcanzar la dignidad exigida a la misma. Así reza en el precepto 4. a) del Texto Refundido de la Ley del Suelo de 2008.

Parece que la traducción práctica a la falta de efectividad del derecho a la vivienda, ha sido la regulación del régimen de las viviendas protegidas o de protección oficial, siendo necesario por parte del legislador el precisar jurídicamente los extremos para la consecución de tal efectividad determinando titular, obligado y contenido del derecho.

\section{Distribución de competencias.}

En el caso de España, el inicial urbanismo centralista quedó afectado por la atribución de competencias plenas a las Comunidades Autónomas derivada de la STC 61/1997.

${ }^{7}$ Entre la literatura existente en base a la peculiaridad del derecho al medio ambiente recogido en el art. 45 de la Constitución, utilizable en relación con el derecho a la vivienda del art. 47 CE, cabe citar a Fernando LÓPEZ RAMÓN, "Derechos fundamentales, subjetivos y colectivos al medio ambiente”, en Revista Española de Derecho Administrativo, núm. 95, 1997. 
La STC 61/1997 ${ }^{8}$ ha marcado, en relación a la distribución competencial, un antes y un después en el encaje práctico de tal atribución. En dicha sentencia, se declaró la inconstitucionalidad de buena parte del Texto Refundido de la Ley del Suelo de 1992, concretamente 177 artículos, y también de la disposición que derogaba la normativa preconstitucional aplicable supletoriamente.

Tradicionalmente, el sistema de distribución de competencias en materia de urbanismo tenía una escasa aplicación práctica, donde el Texto Refundido de la Ley del Suelo de 1976 fue aceptado por las Comunidades Autónomas sin reparo alguno.

Fue con la Ley de Reforma del Régimen Urbanístico de 1990 y el Texto Refundido de 1992, cuando las CGAA reaccionaron en primera instancia y, posteriormente, también con la Ley de Régimen del Suelo y Valoraciones de 1998, interponiéndose diversos recursos de inconstitucionalidad que fueron resueltos por las SSTC 61/1997 y 164/2001 aplicándose, por parte del TC, las reglas de distribución de competencias en la materia de urbanismo.

En ambas sentencias ${ }^{9}$ se argumentó que el Estado no poseía competencias en materia de urbanismo y consecuentemente no podía legislar con carácter supletorio, debido a que solo era posible respecto de la normativa jurídica atinente a una materia por parte del legislador competente; norma supletoria que no podía emanar del Estado por carecer de competencia en materia de urbanismo.

${ }^{8}$ La Constitución es muy determinante al atribuir a las Comunidades Autónomas la competencia sobre la ordenación del territorio y el urbanismo (art. 148.1.3.). Es por ello, por lo que la STC 61/1997 se limitó a destacar lo obvio, declarando que el Estado carece de competencias cobre el urbanismo, siendo ésta de las Comunidades Autónomas. La Sentencia añadió, rompiendo con su anterior doctrina, algo que ya había dicho en STC 118/1996, que el Estado no puede dictar normas supletorias si no ostenta competencia sobre la materia, es decir, que si bien el Estado podía dictar normas a título meramente supletorio, ésta supletoriedad no debía ser entendida como una cláusula universal de atribución competencial, sino una atribución ordenadora, operando como una cláusula de cierre cuyo objeto es la realización del principio de plenitud del ordenamiento jurídico según se precisó en STC 147/1991.

${ }^{9}$ Estas sentencias avalan la clasificación tripartita realizada por la legislación estatal. Para el Tribunal Constitucional, las Comunidades Autónomas podrán regular otra clasificación del suelo que sirvan a objetos diferentes a la regulación básica estatal. Así, y según el propio TC, "nada impide que para fines de gestión o de urbanización el legislador autonómico pueda superponer a la clasificación del suelo como urbano otra clasificación distinta y adecuada a los fines urbanísticos de reforma interior o de completa transformación del suelo". 
Este pronunciamiento, relativo a la supletoriedad del Derecho Estatal, podría encontrar su precedente en la STC 118/1996, de 27 de junio, en materia de transportes terrestres, donde se reseñaba: "Que el Estado no puede dictar normas con eficacia puramente supletoria en materia en la que carezca de todo título competencial, de forma que serían nulas aquellas normas dictadas por el Estado con el único propósito de crear Derecho supletorio del de las CGAA, en materias que sean de exclusiva competencias de éstas".

No obstante, la doctrina sentada por la citada STC 118/1996, encontraría una de sus excepciones en las CCAA de Ceuta y Melilla, que sólo cuentan con potestad reglamentaria en el marco de la legislación estatal, por lo que el Estado tendría competencia para legislar en estos territorios en materia de urbanismo, en la medida en que dicha competencia no ha sido asumida en sus Estatutos de Autonomía.

En resumen, en opinión de FERNÁNDEZ CARBALLAL"10, la "supletoriedad" del artículo 149.3 CE deberá entenderse no como un título competencial que permita al Estado modificar el derecho supletorio existente, sino en el sentido de que la competencia normativa del Estado, en materia de urbanismo, no se excluye del artículo $148.1 .3^{\circ} \mathrm{CE}$, sino que el producto normativo emanado en virtud de dicha competencia estatal es plenamente válido mientras la Comunidad Autónoma no legisle al respecto; momento en el que la Ley autonómica expulsa a la Ley estatal, perdiendo ésta vigencia dentro de su territorio.

Es a partir de este momento cuando se pone en tela de juicio el Derecho Urbanístico Español, viviéndose una situación de permanentes cambios legislativos e incidencias judiciales, derivadas del hecho atributivo de la competencia urbanística a manos de las Comunidades Autónomas.

Lejos de marcar un camino cierto en la regulación del derecho urbanístico ${ }^{11}$, se generó una gran inseguridad jurídica, cargándose de un plumazo la legislación urbanística a nivel estatal. En este mismo sentido, RAMOS MEDRANO consi-

${ }^{10}$ La jurisprudencia constitucional relativa a la distribución de competencias en materia de urbanismo entre el Estado y las Comunidades Autónomas ha sido objeto de cuidadas monografías: Almudena FERNÁNDEZ CARBALLAL, El régimen jurídico del urbanismo en España. Una perspectiva competencial, Madrid, 2001, centra su estudio en el detallado análisis del régimen jurídico de la propiedad urbanística correspondiente a las competencias del Estado.

${ }^{11}$ Entre las primeras reacciones ante la Sentencia del Tribunal Constitucional 61/1997 cabe citar las siguientes: Agustín DE ASÍS ROIG, "El art. 149.1.1. CE como fundamento de la intervención del Estado en materia urbanística", en Luciano PAREJO ALFONSO, El urbanismo hoy, Ma- 
dera que era loable pretender flexibilizar esta rigidez normativa, pero de ahí a pasar al extremo opuesto, a la más absoluta permisibilidad al planeamiento municipal, había una diferencia importante, en la medida en que no era coherente aprovechar el momento de la refundición para deslegalizar esta materia.

En cuanto al reparto de competencias, las CCAA tienen competencia exclusiva, aunque concurrente (que entran en contacto con otras propias de otra administración con objeto distinto, pero próximo al de aquellas) sobre materia urbanística, ordenación del territorio y vivienda reconocidos en el art. 148.1.3 ${ }^{\circ} \mathrm{CE}$. Cada CCAA las asume de manera exclusiva en sus respectivos Estatutos de Autonomía, sin que signifique la incompatibilidad con el reconocimiento que el art. 149.1.1 $1^{\text {a }}$ hace al Estado atribuyéndole la competencia exclusiva en la fijación de las condiciones básicas que tiendan a asegurar la igualdad en el cumplimiento de los deberes básicos inherentes a cada manifestación del dominio.

En resumen, al legislador estatal, de manera restrictiva, le compete establecer las condiciones básicas de la propiedad urbana y la regulación de las valoraciones a efectos expropiatorios, siendo competencia exclusiva de las Comunidades Autónomas las políticas de organización de una ciudad, es decir, las potestades públicas de planeamiento, gestión e intervención sobre el uso del suelo.

Así la legislación estatal aplicable en materia de urbanismo, y en virtud de su título competencial, se contempla en el Texto Refundido de la Ley del Suelo de 2008, donde se integran la Ley del Suelo de 2007 y los artículos vigentes del TR de la Ley del Suelo de 1992, y el reglamento de Inscripciones Urbanísticas en el Registro de la Propiedad de 1997. Incluir también la importancia de las regulaciones urbanísticas incluidas en la legislación reguladora de diferentes sectores como son las relativas a los bienes del Estado, al medio ambiente y al patrimonio cultural.

Añadir, que ese cambio normativo provocado por la sensación de vacío ${ }^{12}$ que dejó la STC 61/1997 y la consecuencia de los enfrentamientos políticos en ca-

drid, 1997; Andrés BETANCOR RODRÍGUEZ, "La cláusula constitucional de supletoriedad: creación y aplicación del Derecho estatal supletorio en defecto de Derecho autonómico"; Tomás RAMÓN FERNÁNDEZ, "El desconcertante presente y el imprevisible y preocupante futuro del Derecho urbanístico español", en Revista Española de Derecho Administrativo, núm. 94, 1997; Eduardo GARCÍA DE ENTERRÍA, "El Derecho urbanístico español a la vista del siglo XXI", en Revista Española de Derecho Administrativo, núm. 99, 1998

${ }^{12}$ Lo que el TC debiera haber hecho, según opinión doctrinal, hubiera sido indagar dentro de las normas básicas de la Ley de 1990, determinando cuáles eran operativas para garantizar un cier- 
da CGAA, no relajaron el panorama, sino que provocó un proceso de adaptación de las CGAA a esa nueva legislación básica del Estado integrada en el TR de 2008.

En relación a las competencias locales en materia de urbanismo, decir que se encuadran en un sistema orgánico conjunto en donde las CGAA asumen el papel de fijación de directrices y control de las mismas. Así, el ámbito competencial municipal ${ }^{13}$ en materia de urbanismo, y concretamente en relación a la disciplina urbanística como eje central del presente artículo, se concreta en la competencia de control de la legalidad y el sometimiento a licencias o autorizaciones preceptivas de los actos de los particulares. Especialmente importante será la competencia relativa a la protección de la legalidad urbanística en relación a las órdenes de ejecución y de demolición derivadas de la Ley del Suelo de 1976 (arts. 184 y 185).

Finalmente, añadir que, sin perjuicio de las regulaciones contenidas en las leyes del suelo y ordenación urbanística ${ }^{14}$ de las Comunidades Autónomas, el Derecho estatal supletorio contiene una completa regulación de la disciplina urbanística en el TR de 1976, anteriormente citado, y en el Reglamento de Disciplina Urbanística de 1978, aprobado por Real Decreto 2187/1978 de 23 de junio. Conforme a este último, la disciplina urbanística comprende un doble ámbito: la protección de la legalidad urbanística y el derecho sancionador en materia urbanística (infracciones y sanciones).

En el caso de Andalucía, el Decreto 60/2010, de 16 de marzo, por el que se aprueba el Reglamento de Disciplina Urbanística de la Comunidad Autónoma de Andalucía (RDUA), ha desplazado al aprobado por Real Decreto 2187/1978, siendo el objeto del mismo la regulación de los instrumentos que habilitan la actividad administrativa en materia de disciplina urbanística.

to estatuto mínimo de igualdad de derechos y deberes. Sin embargo, llevó a efecto, de manera contraria, una identificación de las condiciones básicas con las de principio, estableciendo, consecuentemente, una igualdad formal.

${ }^{13}$ En relación con las competencias municipales en materia de urbanismo, véase Fernando LÓPEZ RAMÓN, "Urbanismo municipal y ordenación del territorio", en Revista Española de Derecho Administrativo, núm. 82, 1994 y como estudio general en la materia puede citarse también "Estudios jurídicos sobre ordenación del territorio", Pamplona, 1995.

${ }^{14} \mathrm{El}$ estudio más completo del régimen de la ordenación del territorio en el Derecho español es el de Antonio Alfonso PÉREZ ANDRÉS, La ordenación del territorio en el estado de las autonomía, Madrid, 1998. 


\section{REGULACIÓN ESTATAL}

Antes de analizar la aportación de la normativa andaluza en relación a la institución reguladora de la situación de fuera de ordenación, es importante hacer un repaso evolutivo partiendo de la Ley Estatal Urbanística del Suelo y Ordenación Urbana de 12 de mayo de $1956^{15}$, la cual fundamentaba la efectividad de los Planes de Ordenación a su obligatoriedad y eficacia vinculante.

En opinión de CORTÉS MORENO ${ }^{16}$, hay que agradecer a esta Ley del Suelo de 1956 la autoría de crear en nuestro derecho urbanístico la figura de "fuera de ordenación", calificando esta situación a aquellas edificaciones e instalaciones existentes con anterioridad a la vigencia del nuevo planeamiento así como las industrias ubicadas en zonas con calificación disconforme con el Planeamiento. Era posible, excepcionalmente, realizar determinadas actividades y obras en estos edificios aunque fueran contrarios a la normativa urbanística (art. 48).

De igual forma fue recogido en el Texto Refundido de la Ley del Suelo de 9 de abril de $1976^{17}$ (arts. 60 y 61). A efectos jurisprudenciales, el Tribunal Supremo considera que la razón de ser del precepto 60 se debe al deseo de que tales edificaciones no prolonguen su existencia más allá de lo que cabe pensar de él. Esta circunstancia no debe colisionar con el hecho de que la falta de ordenación no comporte, inmediatamente, una desaparición del mismo, ni su condena como

${ }^{15}$ La LS 1956 supone un hito en el ordenamiento español. Describiendo esta evolución, hay que destacar la opinión acertada de GARCÍA DE ENTERRÍA Y PAREJO, al decir que constituye el acta fundacional del Derecho urbanístico. De hecho se produce un giro copernicano, desde el momento en que esta Ley nace sin una elaboración doctrinal previa, apareciendo como una isla en el panorama jurídico del Derecho comparado y prestando al Derecho urbanístico una vestidura técnica sin parangón en el mundo.

${ }^{16}$ Describiendo esta evolución véanse Álvaro CORTÉS MORENO, El régimen jurídico de la situación legal de fuera de ordenación. La declaración en situación de asimilación a la de fuera de ordenación en el derecho urbanístico andaluz”, La Ley: Práctica Urbanística, núm. 109, 201 1, donde se pretende analizar de forma global e integral el régimen jurídico aplicable a la situación de fuera de ordenación de edificios y construcciones partiendo de su origen, desde la Ley de Suelo de 1956 hasta el actual Texto Refundido de la Ley de Suelo de 2008, y cómo el Derecho Urbanístico Andaluz ha ampliado el mismo incluyendo supuestos de nueva creación que amplían el denominado régimen de "congelación" urbanística.

${ }^{17}$ Por muchas razones la reforma de 1975 constituyó un paso decisivo en la consolidación del Derecho urbanístico español. Así el Texto Refundido de 1976 domina el panorama urbanístico hasta nuestros días de manera conjunta con los reglamentos que lo desarrollan (Planeamiento, Gestión y Disciplina, publicados entre 1978 y 1979). 
bien económico y social, justificando su existencia y la prestación de los servicios para los que fue erigido hasta que llegue el momento de su desaparición (STS de 8 de julio de 1983).

Es importante añadir que, junto a la definición legal de los edificios erigidos con anterioridad a la aprobación del planeamiento, la jurisprudencia lo extiende a los posteriores a dicha aprobación que resulten disconformes con la ordenación. Así, como dice la STS de 10 de marzo de 1989: "en la medida en que no están ajustadas al ordenamiento urbanístico, merecen ser asimiladas a las construcciones fuera de ordenación definidas en el artículo 60 LS (actual 137), pues ningún obstáculo existe para extender esa calificación a las edificaciones erigidas con posterioridad a la aprobación de la normativa urbanística en tanto no estén acomodadas a ella, con todas sus implicaciones legales".

Posteriormente el Real Decreto Legislativo $1 / 1992^{18}$ de 26 de junio (LS 92), reguló los edificios fuera de ordenación en el artículo 137. La regulación ampliaba este concepto ya que se consideraban aquellos edificios erigidos con anterioridad a la aprobación definitiva del planeamiento urbanístico y no sólo contrarios al Plan General o Parcial.

No obstante, la doctrina mayoritaria entendió que nos encontrábamos en un supuesto de "deslegalización"19, debido a que el segundo apartado del art. 137 del TR de LS 92, en relación con el régimen jurídico de estos edificios e instalaciones en fuera de ordenación, introducía la expresión: "salvo que el propio planeamiento municipal se dispusiera otro régimen". Este exceso refundidor fue criticado por el Consejo de Estado en un informe presentado al Gobierno. En dicho informe se denuncia que el inciso regulado en el art. 137.2 de LS 92, venía siendo consecuencia de una jurisprudencia "reiterada y consolidada" desde el año 1976 lo que exceptuaba la aplicación del art. 60.2 de la Ley de Suelo vigente, dando cobertura legal al régimen jurídico establecido por el antiguo art. 60 del TR del 76 .

\footnotetext{
${ }^{18}$ No obstante, sobre esta Ley también peso la misma maldición que sobre todas las leyes urbanísticas anteriores, debido a que no tuvo aplicación práctica debido a las contestaciones inmediatas de muchas Comunidades Autónomas que veían en peligro sus competencias, pese al carácter supletorio del mismo.

${ }^{19}$ La deslegalización que se efectúa en el TR puede posibilitar que algunos planes pretendan utilizar esta técnica como instrumento beligerante en la transformación de la realidad existente. A modo de ejemplo puede citarse la postura que venía manteniendo el Ayuntamiento de Madrid de no conceder licencias de apertura en los edificios fuera de ordenación.
} 
Por tanto, la consecuencia de esta interpretación jurisprudencial, era excesivamente rígida y limitaba la potestad normativa del planeamiento. Para flexibilizar esta rigidez normativa, sin necesidad de articular una deslegalización efectiva, bastaba con añadir una coletilla diciendo: "salvo que en el propio planeamiento municipal se dispusiera otro régimen más favorable" (para estos inmuebles).

En todo caso, aun en el supuesto de que se admita que el planeamiento está habilitado para regular el régimen jurídico, lo cierto es que deberá ser coherente con la finalidad propia de esta institución, que es la de armonizar el conflicto existente entre la situación real y la propuesta por el planeamiento para el futuro, teniendo en cuenta que la ejecución del plan no es inmediata y entre estas dos fases existe un período, más o menos largo de tiempo, lo que exige el establecimiento de un régimen transitorio "encaminado a obtener la conciliación de dichos intereses, imponiendo limitaciones que, sin impedir el servicio que vienen desempeñando los edificios o industrias, lo congelen en la medida que exige la correcta y futura ejecución del planeamiento".

En cuanto al uso del inmueble, la jurisprudencia en STS de 12 de diciembre de 1988 ha señalado que "las construcciones fuera de ordenación, artículo 60 LS, experimentan las limitaciones en el mismo consignadas relativas a la ejecución de obras..., pero no afectan al uso del inmueble determinado en las ordenanzas vigentes en el tiempo en que fue autorizada la construcción..., ya que el derecho a un aprovechamiento específico de un edificio según la norma vigente en el tiempo en que se autorizó su construcción constituye un derecho adquirido inherente a su titular que es inherente a su situación jurídica urbanística que se integra en los derechos y limitaciones que dimanan de las edificaciones e instalaciones fuera de ordenación".

Respecto de las obras no permitidas se recogían las mismas que la LS 56 y 76 (consolidación, aumento de volumen, modernización o incremento de su valor de expropiación) introduciendo la novedad de que el propio planeamiento lo permitiera. Solo son admisibles las pequeñas reparaciones justificadas por motivo de higiene, ornato y conservación del inmueble.

No obstante, la Jurisprudencia en STS de 11 de febrero de 1992, de forma reiterada, reseña "la necesidad de atender a la naturaleza de las obras a realizar, huyendo, en todo caso, de interpretaciones excesivamente gramaticales, ya que, en sentido estricto, las pequeñas reparaciones no dejan de ser obras de reparación o modernización".

Tras la STC 61/1997, novedosa en la regulación en cuanto a la atribución de competencias se refiere, se declaran inconstitucionales varios preceptos de la LS 
92, quedando vigente sólo el artículo 137.5, que mantendría su vigencia tras la Ley del Suelo 6/1998 de 13 de abril a través de su artículo 2.

Una última referencia normativa la encontramos en la Ley de Suelo 8/2007, integrada en el TR de la Ley del Suelo de 2008, el cual es bastante escueto en la regulación del régimen jurídico de la situación legal de fuera de ordenación, quedando reflejado en sus preceptos 22, 35 y DT $5^{\text {a }}$. En esta Disposición Transitoria cuando se refiere a edificaciones existentes disconformes con la ordenación urbanística vigente "pero de las que ya no procede la adopción de medidas de protección de legalidad urbanística", nos está mostrando de manera indirecta la regulación que desarrolla la legislación urbanística autonómica andaluza que abordaré más adelante.

Haciendo resumen de la regulación establecida en la legislación estatal supletoria podemos sintetizar definiendo la "situación legal de fuera de ordenación" a aquella situación de disconformidad del edificio o instalación preexistente que no implica necesariamente el derribo de los edificios, ni el cese de las actividades para los que fue erigido, manteniendo el "statu quo" y al que se le impide realizar obras que alarguen su vida útil.

Ahora bien, esto no es óbice para que, en caso de que la edificación suponga un peligro contra la seguridad de los ciudadanos, se adopten medidas cautelares dictando orden de ejecución de las obras precisas, llegando incluso a posibilitar la expropiación y demolición de la misma requiriendo, en todo caso, la declaración de utilidad pública declarada por Ley de forma precisa, expresa y tasada. Esta es una competencia exclusiva de las CCAA y en algunos casos, como sucede con la Ley 9/2001 del Suelo de la Comunidad de Madrid, es necesario apoyar la expropiación en algunos de los supuestos expropiatorios contenidos y expresamente admitidos en dicha Ley, aplicable en este municipio.

Dos últimas precisiones importantes son: primero, que están autorizados para declarar una edificación en situación a fuera de ordenación, a partir de la reforma del 76, los instrumentos de Planeamiento General (Plan General, Norma Subsidiaria, etc....) así como los de desarrollo como el Plan Parcial, y en determinados casos los Estudios de Detalle, siempre que sean competentes al respecto; y segundo, que no cabe la situación o consideración parcial, de parte del edificio, de fuera de ordenación, sino que la situación ha de afectar a todo el inmueble y no a parte de él, siendo posible la realización de obras que lo adecuen a la nueva ordenación.

Si cabría la posibilidad de inscribir en el Registro de la Propiedad la situación de anulación de licencia de obra de parte de un edificio, situado en suelo no ur- 
banizable, considerado en fuera de ordenación por sentencia judicial firme. El fundamento jurídico lo encontramos en el art. 1 del Real Decreto 1093/1997 conocido como Anexo al Reglamento Hipotecario, donde se mencionan los actos urbanísticos inscribibles y en cuyo apartado 7 se enumeran las sentencias firmes declarativas de nulidad de las licencias referida a fincas determinadas. A su vez el art. 75 del mismo cuerpo legal, contempla la posibilidad de hacerlo por medio de una nota marginal redactada en virtud de certificación de la sentencia judicial que declare la ilegalidad de la misma. Este argumento se apoya jurídicamente en el precepto 51.7 del Real Decreto Legislativo 2/2008 por el que se aprueba el TR de Ley del Suelo de 2008. En resumen, cabe la posibilidad, por medio de nota marginal en el Registro de la Propiedad, de inscribir las resoluciones judiciales firmes declarativas de licencias ilegales siempre que el propietario haya participado en el proceso.

Haciendo una valoración final a propósito del planeamiento urbanístico municipal y su capacidad de configuración del régimen jurídico de los edificios fuera de ordenación, y de manera continuista a la legislación estatal, la normativa autonómica, según la profesora CARBALLEIRA RIVERA ${ }^{20}$, ampara la posibilidad de que sea el mismo planeamiento municipal el que determine qué inmuebles quedan afectados por esta calificación y régimen jurídico a aplicar.

No obstante, y en atención a la indeterminación de cuál es el instrumento de planeamiento adecuado para determinar tal efecto, la jurisprudencia del Tribunal Supremo respondió de manera indubitada diciendo en STS de 21 de diciembre de 2001:

"el instrumento urbanístico habilitado para calificar de fuera de ordenación es el Plan General de Ordenación Municipal. En ningún caso se acepta el pla-

${ }^{20}$ Por todo lo visto, y en opinión de $\mathrm{M}^{\mathrm{a}}$ Teresa CARBALLEIRA RIVERA, Edificios fuera de ordenación y obras permitidas, Revista de Derecho Urbanístico y Medio Ambiente, núm. 214, 2004, afirmar que el modelo tradicional de regulación de los edificios fuera de ordenación ha quedado parcialmente alterado con las variantes introducidas por las Comunidades Autónomas. Aún así existe, como ya se dijo, una gran identidad conceptual que nos permite extrapolar a la realidad legal vigente algunas de las conclusiones jurisprudenciales que con gran acierto ha venido dictando el Tribunal Supremo en todos estos años. Además, el hecho de que en la actualidad la jurisprudencia sobre esta materia de los Tribunales Superiores de Justicia de las Comunidades Autónomas sea aún escasa por no decir nula, y que la poca que se ha venido dictando se sigue apoyando en la doctrina de este Tribunal, no quiebra su valor sino que le dota de la autoridad y plena vigencia que se merece al tiempo que la relanza como instrumento de gran utilidad para afrontar los nuevos retos de la aplicación de la legislación autonómica. 
neamiento de desarrollo como vía válida para establecer o modificar el régimen jurídico de los edificios fuera de ordenación”.

En la misma sentencia se indica:

"Que la edificación cuestionada no quedó fuera de ordenación por la aprobación de las Normas Subsidiarias, al menos en lo atinente a distancia a linderos y retranqueo que es lo que se cuestiona en este recurso. Es el Estudio de Detalle el que deja fuera de ordenación la edificación, produciendo así un efecto prohibido por el apartado cuarto del precepto invocado que exige que el Estudio de Detalle respete las determinaciones del Plan".

Ahora bien, la posibilidad de configurar, por parte del Gobierno Municipal, el régimen jurídico aplicable no es absoluto e ilimitado.

En primer orden está limitado, según suscriben GONZÁLEZ MARIÑAS y ÁLVAREZ BARBEITO, por el hecho de que debe primar el mantenimiento como fuera de ordenación, antes que la opción del derribo de la edificación por vía expropiatoria.

En segundo lugar, y en aras de la conservación del espíritu de esta figura, hay que dar preferencia al objetivo de equilibrar los intereses enfrentados respecto a otras soluciones urbanísticas definitivas.

\section{REGULACIÓN ANDALUZA}

En relación a la regulación jurídica que de la institución de la situación de fuera de ordenación hace la normativa andaluza ${ }^{21}$, es imprescindible analizar por separado el contenido jurídico de la Ley de Ordenación Urbanística de Andalucía (LOUA) y el del Reglamento de Disciplina Urbanística de Andalucía (RDUA).

\section{El régimen de fuera de ordenación en la LOUA.}

Es preciso aclarar que la LOUA supuso una solución al complejo marco jurídico derivado de la STC 61/1997, y constituye el primer texto legislativo propio

21 Sobre la legislación urbanística de Andalucía, véanse PÉREZ MORENO Y PÉREZ ANDRÉS, La Ley de Ordenación Urbanística de Andalucía, "RAAP", núm. 48, 2002; PÉREZ ANDRÉS, El anteproyecto de Ley de Ordenación Urbanística de Andalucía frente a la Ley de Ordenación del Territorio, "RAAP”, núm. 39, 2000. 
regulador de la materia urbanística en Andalucía. Dicho esto, la LOUA regula el régimen de fuera de ordenación fundamentalmente en dos de sus preceptos: en primer lugar, el artículo 34 de la LOUA ${ }^{22}$ establece las causas que originan la institución de la situación legal de fuera de ordenación y el contenido de la misma cuando hace referencia a los efectos de la aprobación de los instrumentos de planeamiento; y en segundo término, la Disposición Adicional Primera titulada de "La situación legal de fuera de ordenación".

Antes de analizar los mismos, es preceptivo indicar que, con justificación en las diferentes reformas legales operadas desde su promulgación en 2002, la LOUA ha sido recientemente reformada por medio de la Ley 2/2012, de Modificación de la Ley 7/2002 de Ordenación Urbanística de Andalucía, aprobada por el Pleno del Parlamento de Andalucía, en sesión celebrada el día 25 de enero de 2012, con publicación el día 30 de enero de 2012.

\section{A. Concepto y clases de la situación de fuera de ordenación}

Del análisis del artículo 34 de la LOUA, y atendiendo al efecto producido por la aprobación de los instrumentos de planeamiento o, en su caso, de la resolución que ponga fin al correspondiente procedimiento, reseñaremos como presupuestos de hecho para la concurrencia de la situación de fuera de ordenación las tres circunstancias siguientes: primera, la existencia de una obra anterior al nuevo planeamiento urbanístico, pero avalado legítimamente por un plan anterior; segunda, la aprobación de un nuevo instrumento de planeamiento urbanístico; y tercera, la disconformidad entre la obra o uso de la edificación, construcción o instalación y el nuevo planeamiento.

Además este precepto añade otros dos elementos cuanto menos condicionantes a la hora de determinar el régimen aplicable de desordenación. Por un lado, establece dos niveles o grados de aplicación de la situación legal de fuera de ordenación, que son consecuencia de la determinación de que exista una incompatibilidad total o parcial de esta institución con el nuevo planeamiento. Ello, conllevaría la aplicación práctica de distintos regímenes jurídicos que deberán ser identificados por los instrumentos de planeamiento.

22 Resulta obvio que, según la doctrina inspirada en la jurisprudencia, la situación de fuera de ordenación es una calificación urbanística que debe establecerse en el nuevo Plan para evitar las disconformidades implícitas. Así GUTIÉRREZ JULIÁN, Comentarios a la Ley de Ordenación Urbanística de Andalucía, afirma que si las obras son ilegalizables quedan en situación análoga a fuera de ordenación. 
En relación a la existencia de estos dos niveles de desafectación, cabe distinguir uno "absoluto" cuando son totalmente incompatibles con la nueva ordenación, siendo susceptible de aplicación el régimen propio de dicha situación legal, y otro "relativo" cuando sean parcialmente incompatibles y en las que se podrán autorizar, además, obras de mejora o reforma que se determinen, suponiendo en consecuencia un plus de derechos adicionales a favor del propietario. Entre las legislaciones urbanísticas autonómicas que desarrollan expresamente esta clasificación se encuentran las aprobadas en comunidades como Madrid, Castilla-La Mancha, Extremadura o Galicia. Otras comunidades ${ }^{23}$, entre las cuales se encuentra Andalucía, no diferencian entre uno u otro tipo de afectación, aunque sí establecen un régimen diferente de regulación en relación a los inmuebles para los que el nuevo planeamiento prevé su demolición, expropiación, cesión obligatoria o por estar situado en zona de dominio público, del resto de los inmuebles disconformes con el planeamiento por causas diversas como la contrariedad en su altura, edificabilidad o rasante.

La consecuencia jurídica de estos niveles de permisividad, se traduce en una aplicación práctica diferente del régimen jurídico, cuya identificación es preceptiva por los instrumentos de planeamiento, dependientes del grado de incompatibilidad total o parcial con la nueva ordenación. Por tanto, podría aplicarse un régimen donde no se podrán autorizar obras de consolidación, aumento de volumen o aumento de valor de la expropiación y otro régimen más flexible donde de pueda realizar obras de mejora o reforma que se determinen.

Por otro lado, remite al instrumento de planeamiento la determinación, por imperativo legal, de declarar en situación legal de fuera de ordenación las instalaciones, construcciones o edificaciones que ocupen suelo dotacional público o impidan la efectividad de su destino, los cuales son siempre incompatibles con la nueva ordenación.

Lo novedoso de la modificación anteriormente indicada ${ }^{24}$, respecto al precepto que nos ocupa, ha sido la inclusión de un último párrafo del ahora apartado $1^{\circ}$, donde se recoge el régimen "asimilable al de fuera de ordenación", en consonancia con el art. 53.3 del Decreto 60/2010, por el que se aprueba el Reglamento de Disciplina Urbanística de Andalucía, dejando su desarrollo a un futuro Reglamento. En dicha regulación, se deja la puerta abierta a la posibilidad, en

\footnotetext{
23 Andalucía, Aragón, Canarias, La Rioja, Asturias, Castilla y León.

${ }^{24}$ Boletín Oficial del Parlamento de Andalucía no 829 de 30 enero 2012, pág. 11.
} 
base al mantenimiento de las condiciones de seguridad, habitabilidad y salubridad de estos inmuebles, de conceder autorizaciones urbanísticas para obras de reparación y conservación.

Además se añade, con dicha modificación, un segundo apartado por el cual se exige, junto con la correspondiente aprobación del instrumento de planeamiento determinando la incorporación de estas edificaciones, el efectivo cumplimiento, en tiempo y forma, de los deberes y cargas derivadas del mismo.

B. Actuaciones urbanísticas autorizables en edificios de fuera de ordenación

Según acabamos de exponer, las legislaciones urbanísticas autonómicas, reguladoras de los distintos tipos de afectación de los inmuebles declarados en situación de fuera de ordenación, establecen un régimen diferente de actuaciones autorizables, siendo más riguroso en los casos de fuera de ordenación total, admitiéndose exclusivamente las obras de mera conservación y mantenimiento, y más laxo en los casos de disconformidad parcial con el planeamiento, permitiéndose en consecuencia obras de consolidación, mejora o reforma.

En aquellas comunidades, caso de Andalucía, donde hemos verificado la no existencia de tal diferenciación en el grado de afectación, también se constituye un diverso tratamiento de actuación, siendo restrictivo de obras de conservación y mantenimiento en los inmuebles susceptibles, por previsión del planeamiento, de demolición, expropiación, cesión obligatoria o situación sobre dominio público, y amplificado a obras de consolidación, reforma o modernización en los supuestos restantes de mera disconformidad con el planeamiento.

Conviene significar en este apartado, las actuaciones autorizables respecto de las construcciones ilegales, en las que haya transcurrido el plazo previsto para la adopción de las medidas de restablecimiento de la legalidad urbanística, es decir, de las edificaciones declaradas en situación de $\operatorname{asimilada}^{25}$ a fuera de ordenación.

${ }^{25}$ En esta misma línea, se ha pronunciado la Ley 2/2012, de 30 de enero, dando cobertura legal al régimen de asimilable al de fuera de ordenación regulado por el art. 53 RDUA, al establecer en la nueva redacción del art. 34.1 de la LOUA que, "podrán regularse un régimen asimilable al de fuera de ordenación, estableciendo los casos en los que sea posible la concesión de autorizaciones urbanísticas necesarias para las obras de reparación y conservación que exijan el estricto mantenimiento de las condiciones de seguridad, habitabilidad y salubridad del inmueble". 
En principio, en legislaciones autonómicas como la andaluza, se prevé el mismo régimen aplicable a las edificaciones de fuera de ordenación. El RDUA señalaba que, además de las obras de mantenimiento y conservación, se podía también autorizar, de manera excepcional, determinadas obras parciales y circunstanciales de consolidación, apoyado en la regulación de la Disposición Final Primera de la LOUA. A mi juicio, considero injusta está igualdad de criterios al aplicar el mismo régimen a una construcción que fue legal en su origen y deviene disconforme con el cambio de planeamiento, que a aquellas que son fruto de infracciones urbanísticas, donde el paso del tiempo las convierte en inmunes pero no en legales. Por ello, y sustentando la opinión doctrinal mayoritaria, sería de justicia asignar, a este tipo de edificaciones asimilados a fuera de ordenación, el régimen restrictivo fijado para los casos de fuera de ordenación total, siendo autorizable solamente aquellas obras de conservación y mantenimiento como ha determinado la nueva redacción del art. 53.4 del RDUA fijada por la Disposición Final Primera del Decreto 2/2012.

Por último, y en respuesta a la injusticia producida por el diferente régimen de actuaciones permitidas en función de la Comunidad Autónoma en la que nos encontremos, se hace justificable el hecho de que sea el legislador estatal el encargado de elaborar las bases del régimen de fuera de ordenación, derivando en una regulación normativa de desarrollo autonómico más homogénea y unificadora. Esta falta de desarrollo del régimen de fuera de ordenación, unido a la ambigüedad jurídica acerca de cuáles son las obras de mantenimiento y conservación autorizables, acreditan la importancia de la intervención jurisprudencial en la determinación de las actuaciones permitidas sobre estos inmuebles.

Así, estableciendo un claro deslinde entre las obras que conllevan consolidación de las que no a efectos de analizar los actos autorizables en los mismos, la jurisprudencia por un lado establece, que son obras de conservación:

"aquellas reparaciones que exigieren la seguridad, salubridad y conservación de las edificaciones", incluyendo dentro del concepto de obras de reparación, "las necesarias para adaptar el inmueble a las necesidades del propietario, sin alargar la vida útil del edificio, pudiendo comportar modernización pero no la consolidación del mismo" (STS, Sala de lo contencioso-administrativo, Sección $5^{\text {a }}$, de 29 de abril de 2002).

En este sentido, pueden considerarse también como obras de conservación, "la reparación total del tejado y cambio de madera y teja, limpieza de fachadas, reparación del balcón, reforma de cocina, construir un baño, levantar un pequeño muro para impedir un derrumbamiento o aumentar los niveles de seguridad de un local existente, insonorización y estética, entre otros..." (STSJ de 
Castilla y León, de 27 de noviembre de 1998; STS de 8 de febrero de 1994; STSJ de Cataluña, de 2 de junio de 1998 y STSJ de Valencia de 14 de octubre de 1998).

Por el contrario, el pronunciamiento jurisprudencial y doctrinal sobre qué entendemos por obras de consolidación, nos lleva a concretarlo en aquellas obras que dan firmeza y solidez a la edificación existente.

G. Complemento normativo de la regulación jurídica de fuera de ordenación.

Volviendo al régimen jurídico, que de las edificaciones e instalaciones en situación de fuera de ordenación hace la LOUA, indicar que la Disposición Adicional Primera viene a completar esta regulación cuando establece que se considera situación legal de fuera de ordenación "los usos y actividades existentes al tiempo de la aprobación de los instrumentos de planeamiento que resulten disconforme con los mismos". Añadiendo que los instrumentos de planeamiento determinarán el régimen jurídico aplicable no sólo de las construcciones, edificaciones e instalaciones desordenadas por el nuevo plan, sino además de los supuestos de obras clandestinas e ilegales, pero sólo las realizadas en suelo no urbanizable, respecto de las cuales no proceda la restauración del orden jurídico perturbado por haber transcurrido el plazo del artículo 185.1 de la LOUA (seis años). Conviene puntualizar, que el RDUA, en base a una regulación más genérica, amplía las actuaciones clandestinas a cualquier clase de suelo sin especificar que sea exclusivamente para los no urbanizables.

Finalmente, y en atención a los casos en los que el planeamiento guarde silencio e incumpla su deber de determinar el régimen jurídico aplicable, establece unas limitaciones de aplicación por defecto donde determina las reglas de realización de obras de reparación y conservación, así como posibles autorizaciones de obras parciales y circunstanciales de consolidación condicionadas por requisitos de tiempo y forma.

Aunque la regla general es la no permisividad de realización de obras que prolonguen la vida útil del inmueble, la jurisprudencia del Tribunal Supremo, en atención a la particularización de cada caso, autoriza la realización de obras o licencias de uso no ajustadas a las determinaciones del nuevo plan. En nuestra Legislación Autónoma, según lo estipulado por el artículo 7.4 del Decreto 2/2012, y en virtud de una cierta flexibilidad normativa, se permite la concesión de licencias de ocupación para edificaciones fuera de ordenación si mantienen el uso originario o si el nuevo uso es compatible con laordenación vigente al tiempo de la solicitud de la licencia. 
Llegados a este punto, posee gran trascendencia la llamada "cláusula de cierre" del modelo de situación legal de fuera de ordenación que se produciría con la demolición del inmueble. La "congelación" del derecho de conservación del inmueble, se rompería con la ejecución de obras extraordinarias o incompatibles con el modelo de situación de fuera de ordenación lo que determina el estado de ruina y su eliminación por medio del artículo 183 del TR de LS de 1976 declarativo de la ruina urbanística.

La LOUA no contempla expresamente este hecho, ya que en su regulación de la ruina urbanística del artículo 157 se genera un vacío normativo respecto de las edificaciones o construcciones en situación desordenada. Ello permitiría en nuestra Comunidad Autónoma Andaluza, la aplicación de manera supletoria del artículo 183 del TR de LS de 1976, posibilitando la eliminación de esta figura a través de la aplicación de la ruina urbanística.

\section{La declaración en situación de "asimilación" a la de fuera de ordenación del RDUA.}

Una vez vista la regulación jurídica de la situación legal de fuera de ordenación, procede referirse a la situación legal de "asimilación" a la de fuera de ordenación.

Al RDUA le debemos el mérito de utilizar y regular positivamente, por vez primera, en nuestro ordenamiento jurídico esta figura "de la situación de asimilación ${ }^{26}$ a la de fuera de ordenación" que posteriormente glosaré con detenimiento. El Reglamento andaluz no solo viene a completar la regulación jurídica desarrollado por la LOUA, sino que introduce nuevos supuestos materiales y jurídicos como son la generalización de los supuestos de aplicación y el cumplimiento por equivalencia, lo que de inicio choca con la regulación en situación de asimilación de fuera de ordenación por cuanto su objeto es la de dar una alternativa a la reposición de la realidad física alterada como solución "legal" de las mismas.

${ }^{26}$ Precisamente, VARCÁRCEL FERNÁNDEZ, Fundamentos de Derecho Urbanístico, otorga el origen de la categoría en la reacción jurisprudencial frente a lo construido irregularmente y no legalizable. Así lo proclama la STSJ de Andalucía núm. 750/2006 la cual transcribe: “...y por otra es reiterada la jurisprudencia que ha venido afirmando que el transcurso del tiempo no implica más que la Administración pierde sus potestades de exigir al constructor la legalización de lo que sin licencia, o excediéndose de ésta, haya realizado, sin que de ningún modo se produzca la legalización de lo construido "ope legis". Es decir, el transcurso del tiempo no implica que la Administración esté obligada al reconocimiento de la legalidad de las referidas instalaciones, siendo igualmente jurisprudencia reiterada la que asimila las mismas a las construcciones fuera de ordenación." 
Centrándonos en un estudio pormenorizado del artículo 53 del RDUA hay que valorar los siguientes supuestos de hecho:

A. Operatividad del nuevo plazo de prescripción de seis años introducido por la Ley 2/2012, de 30 de enero, que modifica el art. 185.1 de la LOUA.

Un primer supuesto, de mayor extensión en la práctica habitual, contempla la calificación de esta institución de "asimilación al régimen de fuera de ordenación" para aquellas infracciones urbanísticas respecto de las cuales no cabe la restauración de la legalidad urbanística por transcurrir el plazo de seis años a que hace referencia el artículo 185.1 de la LOUA (plazo ampliado como consecuencia de la entrada en vigor, el 28 de febrero de 2012, de la Ley 2/2012, que reforma la LOUA, al pasar de cuatro a seis años).

Constituye un desarrollo de lo previsto en la Disposición Adicional Primera de la LOUA cuando atiende a las "obras clandestinas e ilegales", con el matiz, de referirse a cualquier clase de suelo y no sólo al no urbanizable. Así, las posibles medidas cautelares o definitivas para restaurar el orden jurídico perturbado, solo podrán ser susceptibles de realización durante el transcurso y ejecución de las obras y durante el plazo de seis años desde la efectiva terminación de las mismas. Plazo que es igualmente de aplicación a quien ejerce una acción pública para exigir la observancia de la legislación urbanística, según resulta de la STS de 2 de junio de 2000.

Esta modificación legislativa, adquiere vital importancia, por cuanto es, con la prescripción efectiva de las acciones de protección de la legalidad urbanística derivada de la inactividad material de la Administración (puesto que su no prescripción hace factible la continuación del expediente de disciplina urbanística y su consiguiente restablecimiento del orden jurídico perturbado) cuando se posibilita el reconocimiento de la situación de asimilación a fuera de ordenación.

Respecto del plazo marcado por el art. 185.1 de la LOUA, y aunque la doctrina mayoritaria, resaltando la opinión del Prof. JORDANO FRAGA, considera tal plazo como de caducidad ${ }^{27}$, entiendo que habría que hacer una distinción

${ }^{27}$ Doctrinalmente, en el sentido de afirmar la caducidad, la opinión es mayoritaria según CASTILLO BLANCO, Régimen jurídico de las actuaciones Urbanísticas sin Título Jurídico Autorizante; PAREJO ALFONSO, La disciplina urbanística; GUTIÉRREZ JULIÁN, Comentarios a la Ley de Ordenación Urbanística de Andalucía. Doctrina que viene apoyada en numerosa jurisprudencia según clarifica en STSJ de la Comunidad Valenciana núm. 777/2005 de 28 de octubre. 
entre el hecho de que la Administración competente hubiera incoado expediente de restitución del orden jurídico perturbado con la intención de adoptar las medidas necesarias para la legalización de la infracción urbanística, del hecho en que dicha Administración no hubiese iniciado tal procedimiento. En el primer caso, entiendo que estaríamos en un supuesto de plazo de caducidad en el momento que transcurrieran los seis años sin que la Administración hiciese efectiva la ejecución del procedimiento de restitución. En cambio, pienso que si nos encontrásemos en el segundo supuesto, estaríamos hablando de un supuesto de prescripción por el transcurso del tiempo sin que la Administración competente ejerciera su obligación de iniciar el procedimiento de protección de la legalidad urbanística.

En este sentido, especial importancia adquiere el hecho de probar la acreditación de la completa "terminación" de la edificación, para aquellas situaciones de ejecución de edificaciones al margen de la correspondiente licencia urbanística. Es por ello, que la jurisprudencia otorga la carga de la prueba a quien voluntariamente realiza en situación de clandestinidad la materialización de dichas obras y así consta en STS de 25 de febrero de 1992. De este hecho derivan las SSTS de 14 de mayo de 1990; de 16 de mayo de 1991 y de 3 de enero de 1992, las cuales impiden la obtención de ventajas probatorias a quien crea las mencionadas situaciones de ilegalidad.

No obstante, el apartado segundo del artículo 185 de la LOUA, establece unos supuestos tipificados donde no operaría en ningún caso dicho plazo prescriptivo, siendo posible la reposición de la realidad física alterada en cualquier momento. Por consiguiente, la acreditación del transcurso de los seis años, constituirá el elemento clave para determinar si opera o no la situación de asimilación a fuera de ordenación. Ello, sin que tenga especial transcendencia la tipología del suelo, salvo en los casos indicados en el artículo 185.2 de la LOUA.

En estos casos, y a efectos de la imprescriptibilidad de la acción regulada en el art. 185.2 de la LOUA, el Tribunal Superior de Justicia de Andalucía en sentencia de 4 de junio de 2001, determina que "ha de observarse la clasificación del suelo en el momento en que se realizaron los actos o usos y no la posible clasificación posterior", operando, en consecuencia, el principio "tempus regit actum" donde los actos se aplican de conformidad con las normas vigentes al momento de su producción.

En este mismo sentido, es conveniente indicar la Resolución de la Dirección General de Registros y Notarios 2/2009 estimativo de un recurso interpuesto por un notario de Albuñol contra la negativa de un Registrador de la Propiedad de Motril a inmatricular una escritura de donación. El fundamento jurídico era 
que, si bien en su calificación el plazo de restablecimiento de la hipotética infracción urbanística había transcurrido, había que demostrar que el supuesto de hecho no se encontraba entre las excepciones contempladas en el art. 185.2 de la LOUA.

B. Del cumplimiento por equivalencia.

Un segundo supuesto, dispone que se encuentren en idéntica situación de asimilación a fuera de ordenación, las obras, instalaciones, edificaciones y construcciones en los casos de imposibilidad legal o material de ejecutar la resolución de reposición de la realidad física alterada. Aquí el artículo 53.2 del RDUA nos remite al 51 donde se prevé la posibilidad, por parte del órgano competente, de adoptar medidas necesarias aseguradoras del efectivo restablecimiento del orden jurídico perturbado. Así, tras emitirse los preceptivos informes técnicos y jurídicos, valorando la imposibilidad legal o material, se fijará una "indemnización por equivalencia" consistente en la entrega de cantidad en metálico o la cesión de terreno o edificación equivalente en aprovechamiento efectivo sin título. En este punto, el legislador, tomando como base la posibilidad de inejecución de resoluciones judiciales (artículos 18 LOPJ y 105 LJCA), deja a salvo la potestad jurisdiccional de "hacer ejecutar lo juzgado".

No obstante, conviene advertir el hecho de que toda resolución acordando el cumplimiento por equivalencia, dejando en consecuencia a la edificación en situación de asimilada a fuera de ordenación, debe respetar las determinaciones siguientes:

- Evitar el quebranto patrimonial del municipio, estableciendo tanto la indemnización por equivalencia correspondiente a la resolución de inejecución, como los bienes o intereses alterados por los actos objeto del procedimiento de reposición de la realidad física alterada.

- Salvaguarda del principio de seguridad jurídica, por medio de la valoración del aprovechamiento urbanístico de las infracciones urbanísticas materializadas, según los criterios de valoración adaptados a la legislación vigente, presumiendo su realización con título.

- Compatibilidad con las sanciones urbanísticas procedentes, de suerte que el pago de la indemnización correspondiente se abone con independencia de las sanciones urbanísticas fijadas por las infracciones cometidas, siendo susceptible de aplicación, a los particulares infractores, el beneficio de la reducción contemplado en el artículo 208.2 de la LOUA. 
- Vinculación a los Jueces y Tribunales integrantes del Poder Judicial, ya que la inejecución de sentencias firmes, por el cumplimiento por equivalencia según la normativa aprobada por los planificadores urbanísticos, conlleva aparejada la regularización según los tramites y cauces previstos del artículo 18 de la LOPJ y del 105 de la LJCA.

A esta posibilidad se refiere la STS de 28 de junio de 2006, dictada en recurso $2445 / 2005$, la cual ante la orden de demolición de un complejo residencial confirmado judicialmente, y su imposible ejecución por la ocupación de terceros adquirentes de buena fe (de lo edificado ilegalmente) y al principio de proporcionalidad, concluye que "es procedente la ejecución de la sentencia mediante indemnizaciones sustitutorias de la ejecución "in natura" como única forma de que el favorecido por el fallo obtenga la tutela judicial efectiva, indemnización que siendo sustituta de la ejecución propiamente dicha, no deja de ser ejecución de la sentencia”.

Con la modificación producida en la LOUA, incluida en Disposición Final Primera del Decreto $2 / 2012^{28}$, por el que se regula el régimen de las edificaciones y asentamientos existentes en suelo no urbanizable en la Comunidad Autónoma de Andalucía, se añade la condición de la satisfacción íntegra de dicha indemnización fijada por equivalencia para declarar la situación de asimilación a fuera de ordenación en estos casos.

Es materia cuestionada la naturaleza jurídica de tal ingreso por equivalencia. En mi opinión, y asintiendo con una parte de la doctrina destacando RIQUELME GARCÍA y GALLEGO ALCALÁ, considero que estamos ante multas coercitivas impuestas por ejecución forzosa destinadas, a tenor del artículo 41 RDUA, a la cobertura de los gastos de ejecución subsidiaria de la resolución, más intereses y gastos de ejecución. Tal pago será además una condición de derecho para otorgar licencias en bienes que están declarados en situación de asimilación a fuera de ordenación conforme la nueva redacción del artículo 53.3 del RDUA, anteriormente contenida en el último párrafo del artículo 53.5 del RDUA.

Ambos apartados anteriormente citados, limitan y condicionan a la Administración a la hora de garantizar y reponer el orden jurídico perturbado, ya que imposibilita la reacción de la Administración una vez transcurrido el plazo de seis años y además imposibilita su reposición por la consecución de causas sobrevenidas de naturaleza legal o material.

\footnotetext{
${ }^{28}$ Boletín Oficial de la Junta de Andalucía no 19 de 30 enero 2012, pág. 28.
} 
Estas circunstancias de "asimilación" desarrolladas por el artículo 53 del RDUA, chocaban con los efectos declarados por la "situación legal de fuera de ordenación" desarrollados en la LOUA, los cuales tienen por finalidad la desaparición de los elementos discordantes que la motivaron.

Así, era de especial importancia, por su controversia, la concreción de las obras permitidas en las edificaciones y construcciones en situación de asimilación a la de fuera de ordenación, más aún de acuerdo a su limitado régimen de aplicación; régimen que en ningún caso podrá suponer la privación y disfrute del derecho de propiedad sobre dicho inmueble. Según el párrafo anterior, manifiesto que "chocaban" porque, según la redacción anterior del art. 53.4 del RDUA, se permitían, excepcionalmente, obras parciales y circunstanciales de consolidación conforme al destino establecido. Este es el matiz que, a mi juicio, resaltaba respecto de la regulación derivada de la Disposición Adicional Primera de la LOUA. En dicha D.A.P., se hacía solo referencia a las licencias urbanísticas de obras de reparación y conservación. En cambio, el antiguo art. 53 del RDUA incorporaba la posibilidad a solicitar estas licencias incluyendo las de primera ocupación o utilización.

Así, el artículo 53.4 del RDUA aplicaba un régimen jurídico más flexible permitiendo incluso la realización de obras parciales y circunstanciales de consolidación, lo que nos llevaría a pensar que en cierta medida era un premio para el infractor y determinaría, en última instancia, la pervivencia de las edificaciones o construcciones que provienen de irregularidades urbanísticas. Actualmente, el nuevo precepto 53.4 del RDUA, solo contempla la posibilidad de autorización de las obras de reparación y conservación por motivos de mantenimiento de las condiciones de seguridad, habitabilidad y salubridad del inmueble.

No obstante, es preciso matizar, en relación a las obras admisibles y en analogía a la situación legal de fuera de ordenación, que la jurisprudencia había destacado, de forma reiterada, en STS de 11 de febrero de 1992, "la necesidad de atender a la naturaleza de las obras a realizar, huyendo, de interpretaciones excesivamente gramaticales, ya que, en sentido estricto, las pequeñas reparaciones no dejan de ser obras de reparación o modernización".

C. Necesario reflejo registral de las limitaciones del régimen de asimilado a fuera de ordenación

Tradicionalmente, la normativa estatal ha sido la encargada de establecer legalmente las determinaciones preceptivas de hacer constar la situación de fuera de ordenación de un inmueble en las escrituras de transmisión ${ }^{29}$ y facultar a los

${ }^{29}$ Motivos de seguridad jurídica fueron los que justificaron la regulación adoptada por la Ley del 
terceros adquirentes de la posibilidad de rescindir los contratos y exigir la correspondiente indemnización por los daños y perjuicios causados por la no inscripción de la misma.

En relación a la figura de edificaciones asimiladas a la de fuera de ordenación, el TRLS 2008, en su art. 20.4 b), y según redacción otorgada por el Real Decreto Ley 8/2011, de 1 de julio, articula un procedimiento específico donde debe aportarse al Registrador de la Propiedad la resolución finalizadora del procedimiento de asimilación, reflejando literalmente las condiciones a que están sujetas, con expresión en particular de las obras de reparación y conservación autorizadas para el efectivo mantenimiento de las condiciones de sostenibilidad y habitabilidad de la instalación, construcción o edificación afectada (art. 53.5 RDUA).

En la nueva redacción del art. 53.5, reseñada en Decreto 2/2012, y según legislación notarial y registral, adquiere carácter preceptivo el reconocimiento de situación asimilada a fuera de ordenación a la hora de poder inscribir este tipo de edificaciones en el Registro de la Propiedad, indicándose, a su vez, régimen jurídico aplicable y condiciones a adoptar por las mismas. El argumento de este precepto lo encontramos en la condición suspensiva de las licencias otorgadas a su constancia registral, es decir, que para la eficacia de una licencia de ocupación de una edificación "prescrita", es requisito o condición necesaria la previa inscripción de la misma en el Registro de la Propiedad. No obstante, cuestión polémica ha supuesto el hecho de que se exija licencia de obra y de ocupación para acceder al registro de aquellas obras que han cumplido escrupulosamente con las determinaciones urbanísticas, mientras que para las obras ilegales, pero prescritas, baste una simple certificación registral quebrando en consecuencia el principio de igualdad y de seguridad jurídica.

A su vez, el propio Decreto 2/2012, en Disposición Transitoria declara que aquellas edificaciones declaradas en situación de AFO e inscritas con anterioridad a la entrada en vigor del Real Decreto 8/2011, sin mención expresa de las condiciones derivadas de este régimen, será la Administración competente la que inste dicha constancia en la forma y con los efectos previstos en la legislación notarial y registral correspondiente.

Suelo de 1956, cuyo art. 50.1) obligaba al vendedor de edificios e industrias fuera de ordenación, a hacer constar expresamente tal calificación en el correspondiente título de enajenación. Igual suerte aplicaría el TRLS de 1976, siendo el TRSL de 1992 el artífice de "flexibilizar" este régimen al incorporar la denominada "deslegalización" de la figura, por cuanto su art. 137.2 atribuía al Planeamiento, como norma reglamentaria, la posibilidad de modificar el régimen legal de fuera de ordenación. 
Al hilo de esta cuestión, y salvando el agravio comparativo producido respecto de las edificaciones declaradas en situación de fuera de ordenación, conviene destacar la importancia que las recientes resoluciones adoptadas por la Dirección General de Registro y Notariado han venido adoptando en relación a la consideración de innecesariedad respecto a la acreditación de la Licencia de Primera Ocupación de las edificaciones asimiladas a la hora de acceder al Registro. Concretamente las Resoluciones de 24 de marzo; 14 de abril y 4 de mayo de 2011, dispensan de la exigencia de aportación de la licencia de obras, a que se refiere el art. 46 del Real Decreto 1093/1997, a los efectos de la inscripción registral, pues su objeto, entre otros, atiende a verificar la ordenación urbanística aplicable en cuanto al uso previsto para el edificio.

Finalmente, conviene reseñar que el proyecto de modificación de la LOUA, añade un nuevo apartado $3^{\circ}$ del art. 176 donde se dice que "la Notaría podrá solicitar de la Administración pública competente información telemática o, en su defecto, cédula o informe escrito expresivo de su situación urbanística, de los deberes y obligaciones a cuyo cumplimiento estén afectas así como, especialmente, de su situación de fuera de ordenación o asimilada, de las medidas de protección de la legalidad urbanística y de restablecimiento del orden jurídico que pudieran alcanzarles". La Notaría incluirá esta información en la correspondiente escritura, informando de su contenido a las personas otorgantes y remitirá a la Administración competente, para su conocimiento, copia simple para las que hubieran solicitado y obtenido información urbanística.

\section{Adaptación de la LOUA al RDUA.}

Llegados a este punto del camino, es importante puntualizar el hecho de que el Parlamento Andaluz pretenda, sin entrar a valorar los criterios de oportunidad políticos al respecto, modificar la Ley 7/2002 (LOUA) por medio de un procedimiento de urgencia presentando el Proyecto de Ley en Sesión de la Mesa del Parlamento el 9 de Noviembre de 2011, siendo, consecuentemente, aprobada por el Pleno del Parlamento de Andalucía, en sesión celebrada el día 25 de enero de 2012, con publicación de 30 de enero, la Ley de modificación de la Ley 7/2002 de Ordenación Urbanística de Andalucía.

Por ello, el legislador andaluz se ha visto obligado a modificar la LOUA en su última sesión parlamentaria de la pasada legislatura, posibilitando así la publicación del Decreto 2/2012 reguladora de las viviendas ilegales en suelo no urbanizable; Decreto que incluye una serie de enmiendas aclaratorias de aquellos artículos de la Ley que entraban en conflicto con el mismo. Entre la batería de modificaciones propuestas, la que nos interesa destacar, por tratarse de la materia troncal de lo aquí suscrito, es la que modifica el apartado b) del art. 34.1, siendo, 
en mi opinión, una clara adaptación de lo regulado en la LOUA a lo contemplado por el RDUA.

Así, en su último párrafo, contempla la inclusión de la regulación reglamentaria de un régimen asimilable al de fuera de ordenación, estableciendo los casos de autorizaciones urbanísticas necesarias para las obras de reparación y conservación. Además añade un apartado 2 al art. 34, donde se determina la necesidad, junto al instrumento de planeamiento de incorporación, del cumplimiento de los deberes y cargas derivados del mismo.

Es evidente el giro legislativo que se pretende con la modificación de este precepto para adecuarlo a la realidad jurídica existente a raíz de la aprobación del RDUA. Así en consonancia con el artículo 53 del RDUA, el artículo 34 b) de la LOUA pretende recoger el régimen asimilable al de fuera de ordenación, dejando a un futuro desarrollo Reglamentario su regulación jurídica. Considero positiva esta adaptación legislativa, por cuanto supone una solución parcial de los problemas surgidos en la actividad residencial en el tipo de suelo no urbanizable, en concreto para aquellas edificaciones existentes que se encuentran en situación de asimilación a fuera de ordenación. Además, subsana los efectos negativos ocasionados por una regulación rígida respecto de las soluciones propuestas en su día por el RDUA.

\section{Decreto andaluz 2/2012 sobre regulación del régimen de las edificaciones y asentamientos existentes en suelo no urbani- zable.}

De vital importancia jurídica ha supuesto el Decreto aprobado en Consejo de Gobierno Andaluz el 10 de Enero de 2012, y publicado en el BOJA con fecha 30 de enero, por el cual se regula el régimen de las edificaciones y asentamientos existentes en suelo no urbanizable, estableciendo vías para su "legalización" (en la medida de lo posible) cuando lo permitan las circunstancias físicas y jurídicas y acorde a lo regulado por la LOUA. Es obvio que el objeto de este Decreto es la regulación jurídica de las edificaciones aisladas existentes o agrupadas en asentamientos urbanísticos en suelo no urbanizable. No es más que la regularización del problema que viene arrastrando nuestra realidad urbanística desde, principalmente, los años 70 estableciendo un régimen jurídico para dichas edificaciones. Se estima que nueve de cada diez viviendas edificadas en suelo no urbanizable acreditarán su situación en virtud de este Decreto, de las cuales un 10\% regularizarán su situación definitivamente y un $80 \%$ no se legalizarán, pero si reconocerán su realidad jurídica o quedarán en situación de asimilación a fuera de ordenación, traduciéndose en la posibilidad de acceder a los servicios básicos necesarios de habitabilidad. 
Además se facilita la rapidez del tráfico inmobiliario consecuencia de la posibilidad de inscripción en el Registro de la Propiedad, dando seguridad jurídica a dichas edificaciones y permitiendo que los posibles compradores y las entidades financieras puedan conocer en todo momento la existencia y características de las mismas. Tras la primera lectura, parece claro que lo único que el Decreto va a conseguir es una catalogación y clasificación de la situación real existente, pero sin soluciones prácticas a corto plazo. Aun así, considero que supone un avance importante a efectos de superar la situación de permanente ilegalidad a la que parecían estar abocadas este tipo de edificaciones, superando ese limbo jurídico y favoreciendo la solución de problemas de dotación de infraestructuras, servicios y registro sufridos.

A. Soluciones abordadas para las edificaciones existentes en el suelo no urbanizable.

El Decreto 2/2012, a través del establecimiento de distintos tipos de viviendas, adaptándolas en función de sus características a la ordenación urbanística, encomienda la regularización de las edificaciones existentes en suelo no urbanizable al instrumento de Planeamiento General, por cuanto serán los propios municipios los encargados de solucionar los problemas territoriales y urbanísticos relacionados con la determinación de dotaciones, servicios, conexión de infraestructuras, impacto ambiental, etc... Así, efectúa una clasificación de estas edificaciones según su ubicación en el medio físico, diferenciando en su art. 2.2 entre las Edificaciones Aisladas, los Asentamientos Urbanísticos (parcelaciones con entidad suficiente como para necesitar dotaciones y servicios colectivos) y los denominados ámbitos de Hábitat Rural Diseminado (edificaciones con usos y actividades vinculadas al medio rural que también requieren de servicios públicos).

Las edificaciones declaradas en situación legal de fuera de ordenación y las reconocidas en régimen asimilado al de fuera de ordenación, se encuadrarían dentro de las edificaciones aisladas, desarrollando el Decreto 2/2012, en sus preceptos 9 a 12, un detallado y prolijo tratamiento a la hora de declarar como asimiladas a la situación de fuera de ordenación a las edificaciones situadas en el suelo no urbanizable del territorio andaluz.

Por lo que respecta al tratamiento que dispensa el Decreto en relación a las edificaciones aisladas en situación legal de fuera de ordenación, incluye las disconformes con el ordenamiento vigente, pero que fueron construidas con autorización administrativa, con posterioridad a la Ley 19/19750, o sin autorización

${ }^{30}$ Art. 3.1. B, a) del Decreto 2/2012, de 10 de enero, por el que se regula el régimen de las edi- 
administrativa pero con anterioridad a dicha Ley. El régimen jurídico aplicable sería el mismo que viene determinado por la LOUA y el RDUA.

Además, y como novedad respecto al borrador del propio Decreto, se consideran en situación legal de fuera de ordenación, aquellas edificaciones no conformes con la ordenación territorial y urbanística, ubicadas en suelo no urbanizable de especial protección, en terrenos de la zona de influencia del litoral o en suelos con ciertos riesgos pero que fueron construidos con licencia urbanística de conformidad con el ordenamiento vigente en el momento de la construcción ${ }^{31}$.

En cuanto a las edificaciones aisladas en régimen asimilado al de fuera de ordenación, se incluyen las disconformes con el ordenamiento vigente, que fueron construidas sin autorización administrativa, pero sobre las que la Administración ya no puede incoar el expediente de restablecimiento de la legalidad urbanística por prescripción de la infracción urbanística ${ }^{32}$. Hablamos de plazo de prescripción, porque supone el transcurso de los seis años (a que hace referencia la LOUA en su art. 185.1) desde su terminación, sin que se haya iniciado, por parte de la Administración, el expediente de restablecimiento de la legalidad. Es aquí donde se produce la gran novedad de este Decreto al incorporar la regulación de estas edificaciones asimiladas a la fuera de ordenación. En mi opinión, es una novedad anunciada de antemano en la modificación de la LOUA, donde se incluye presumiblemente esta figura desarrollada por el RDUA.

También se incluyen, al régimen asimilado al de fuera de ordenación, las disconformes en suelo no urbanizable de especial protección, en terrenos de la zona de influencia del litoral o en suelos con ciertos riesgos, pero construidos sin licencia o contraviniendo las condiciones y se hubiere agotado el plazo para adoptar medidas de protección ${ }^{33}$.

ficaciones y asentamientos existentes en suelo no urbanizable en la Comunidad Autónoma de Andalucía.

31 Art. 3.2. a) del Decreto 2/2012, de 10 de enero, por el que se regula el régimen de las edificaciones y asentamientos existentes en suelo no urbanizable en la Comunidad Autónoma de Andalucía.

${ }^{32}$ Art. 3.1. B, b) del Decreto 2/2012, de 10 de enero, por el que se regula el régimen de las edificaciones y asentamientos existentes en suelo no urbanizable en la Comunidad Autónoma de Andalucía.

33 Art. 3.2. b) del Decreto 2/2012, de 10 de enero, por el que se regula el régimen de las edificaciones y asentamientos existentes en suelo no urbanizable en la Comunidad Autónoma de Andalucía. 
A efectos de identificar las edificaciones aisladas en suelo no urbanizable, se requiere la previa delimitación por el PGOU, llevándose a cabo, de manera subsidiaria, a través de avance de planeamiento por parte del Ayuntamiento, en aquellos casos de ausencia del Plan General o si éste no contemplara, de manera precisa, la identificación correspondiente.

\section{a). Del "efecto directo horizontal" de las Directivas medioambientales.}

Llegados a este punto, y respecto a la polémica suscitada sobre la existencia de ciertas categorías de suelo de especial protección en municipios sin planeamiento, es preceptivo indicar que, frente a las tesis que defienden, desde un punto de vista formal, la no consideración de suelo no urbanizable de Especial Protección al suelo que no ha sido objeto de transposición del correspondiente régimen de protección ambiental internacional, cabe apelar en contrario los principios de prevalencia de la protección ambiental sobre la ordenación territorial y urbanística, de igualdad y la propia naturaleza reglada del bien jurídico a proteger.

A mi juicio, y tomando como base la oponibilidad a terceros de la condición de especial protección desde el instante que fue pública y, en consecuencia, susceptible de ser conocida por los particulares, cabe afirmar el efecto directo horizontal $^{34}$ de las Directivas medioambientales, sustentado por la diversa jurisprudencia emanada del Tribunal Superior de Justicia de Andalucía, del Tribunal Supremo y del Tribunal de Justicia de la Comunidad Europea que insisten en la retroacción del efecto cautelar de la protección al momento en que se elabora la lista de lugares a proteger por las Comunidades Autónomas: “...dicha lista no es una mera propuesta neutra, sino un acto administrativo que habilita y obliga a la propia Comunidad Autónoma a adoptar medidas de protección adecuada para los lugares incluidos... pone una condición necesaria y suficiente para crear en la Comunidad Autónoma la obligación de adoptar medidas de protección adecuadas".

Por tanto, y teniendo en cuenta que la especial protección de un suelo puede venir determinado por un grupo normativo específico, en este caso el medioambiental, no es necesaria para determinar la validez y eficacia de la especial pro-

34 JORDANO FRAGA, Jesús. "Efecto directo horizontal" de determinadas Directivas Ambientales: la consagración jurisprudencial de la invocabilidad por particulares de las directivas en relaciones triangulares. (Comentario a la Sentencia del Tribunal de Justicia (Sala Quinta) de 7 de enero de 2004 en el asunto c-201/02). Revista electrónica Medio ambiente y Derecho. 
tección la aprobación previo de ningún instrumento de planeamiento. Por ello, es importante resaltar lo señalado por el Prof. JORDANO FRAGA, donde "El efecto directo horizontal de determinadas directivas ambientales va constituir un arma decisiva para la lucha contra los retrasos endémicos - en nuestro caso, en la tramitación de los PGOU o la propia transposición defectuosa. Pero también respecto de actos de aplicación que como dice la jurisprudencia estudiada supongan que las autoridades legislativas o administrativas de un Estado miembro sobrepasen el margen de apreciación que les confieren dichas disposiciones pues los particulares podrán invocarlas ante los órganos jurisdiccionales de dicho Estado en contra de las autoridades nacionales y obtener así de éstas la inaplicación de las normas o medidas nacionales incompatibles con las mencionadas disposiciones".

En relación a la identificación de las edificaciones aisladas, resulta cuanto menos llamativo el hecho de ser una "definición por exclusión", puesto que serán edificaciones aisladas aquellas no ubicadas en ningunos de los asentamientos delimitados, previamente, por el PGOU o, en su defecto, por el Avance de planeamiento realizado por el Ayuntamiento correspondiente. Parece obvio que, en relación a la situación económica actual de la Administración y de los Ayuntamientos, este primer plazo de clasificación de las edificaciones puede dilatarse en el tiempo, traduciéndose en una situación de inseguridad jurídica al respecto.

\section{b). Importancia del art. 8.2 del Decreto.}

La otra cuestión generadora de polémicas, a la hora de declarar la situación de asimilación a fuera de ordenación, han supuesto las edificaciones ubicadas en asentamientos urbanísticos, resultando, a priori, no encuadrables en dicha clasificación por carecer de la condición esencial, la de ser edificación aislada, para estar exentas del procedimiento de protección de la legalidad urbanística y restablecimiento del orden jurídico infringido por transcurso del tiempo. La interpretación a realizar del precepto 8.2 del Decreto 2/2012, supone el reconocimiento de la declaración de asimilación a fuera de ordenación, exceptuando consecuentemente su demolición, a aquellas edificaciones que eran "originariamente" aisladas y, como consecuencia de la transformación urbanística, devinieron ubicadas en parcelaciones posteriores a la LOUA, siempre que hubieran sido susceptible de reagrupación de las parcelas según lo reseñado en el artículo 183.3 de la LOUA, pudiendo ser declaradas, en este caso, AFO.

Salvo en estos casos, la situación jurídica de las edificaciones, construcciones y obras en el ámbito de una parcelación urbanística en suelo no urbanizable realizada con posterioridad a la LOUA, cambiaría, sólo y exclusivamente, con la modificación de la clasificación del suelo declarado por instrumento de planea- 
miento o por integrarse en un Hábitat Rural Diseminado en suelo no urbanizable, con el correspondiente cumplimiento de las determinaciones oportunas.

Conviene advertir, como solución a una situación de fraude legal producida por el tratamiento masivo e individualizado de aquellos asentamientos existentes desgajados del núcleo urbano, la importancia de la delimitación de la condición de "aislada" de las edificaciones por cuanto su pertenencia al conjunto sustantivo de la ciudad, comporta un tratamiento específico y global. Así, adquiere especial relevancia el hecho de que sea el PGOU, o, en su defecto, el avance del Ayuntamiento, quien determine la definición de las edificaciones aisladas.

Otra novedad del Decreto ha sido la incorporación de los asentamientos urbanísticos como suelos urbanos no consolidados o como suelos urbanizables ordenados o sectorizados por medio del PGOU. Ello conllevaría, por parte de los propietarios de las edificaciones, la obligación de soportar las cargas de urbanización y la obtención de dotaciones y equipamientos que dichos Planes Generales dispongan para los referidos suelos ${ }^{35}$. Una consecuencia previsible que acarrea este proceso regularizador de viviendas ilegales, está siendo la negativa o imposibilidad, por parte de los propietarios de estas edificaciones, de correr con los gastos económicos consecuencia del mismo.

Finalmente, indicar que existe un problema añadido ya que para poder inscribir en el Registro de la Propiedad cualquier acto administrativo que establezca una construcción como "asimilada al régimen de fuera de ordenación", al ser las competencias del Registro de la Propiedad de carácter estatal y no autonómico, la legislación estatal debería incluir, en primer lugar, dicha figura legal en su legislación puesto que solo existe la figura "fuera de ordenación" y no la de "asimilado".

B. Procedimiento general de declaración de situación de asimilación a fuera de ordenación.

Lo verdaderamente novedoso del Decreto, ha sido la regulación del procedimiento ${ }^{36}$ para el reconocimiento de la situación de asimilado al régimen de fue-

35 Es muy expresivo, en este sentido, el Informe Especial del Defensor del Pueblo Andaluz al Parlamento de Andalucía, Las urbanizaciones Ilegales en Andalucía, $1^{\text {a }}$ edición, Defensor del Pueblo Andaluz, Sevilla, 2000, cuya transcripción literal reproduce: "Las cargas urbanísticas deben asumirlas quienes van a ser beneficiarios más directos de los procesos de regularización...".

${ }^{36}$ Arts. 9, 10, 11 y 12 del Decreto 2/2012, de 10 de enero, por el que se regula el régimen de las edificaciones y asentamientos existentes en suelo no urbanizable en la Comunidad Autónoma de Andalucía. 
ra de ordenación, correspondiendo al Ayuntamiento ${ }^{37}$ el reconocimiento de esta situación y cuyo inicio podrá hacerse de oficio o por medio de solicitud presentada por el titular de la edificación, llegándose, incluso, a poder presentar soluciones coordinadas por existir proximidad entre las distintas edificaciones afectadas.

En relación a la instrucción del procedimiento, estará el Ayuntamiento autorizado a solicitar cuantos informes técnicos y jurídicos sean necesarios a los órganos y entidades administrativas correspondientes, pudiendo requerir la realización de obras e instalaciones indispensables con objeto en una posterior contratación de los servicios básicos e incluso aquellas que resulten necesarias para garantizar la seguridad, salubridad y ornato, sin excluir las imprescindibles para evitar el impacto negativo de la edificación sobre el paisaje del entorno.

Conviene significar que, por adaptación de la normativa autonómica a la Directiva de Servicios, se presume una modificación de los preceptos del RDUA que regulan los visados obligatorios, por cuanto la documentación a presentar para obtener la declaración de asimilado a fuera de ordenación deberá ser visada en los casos en que los exija la normativa estatal. Actualmente son obligatorios los visados para los proyectos de ejecución de edificaciones, las declaraciones de obra nueva y los proyectos de legalización.

Por lo que respecta a las edificaciones en el suelo no urbanizable, la novedad más significativa a la hora de reconocer por parte del municipio correspondiente la situación de asimilación a fuera de ordenación, la constituye la constancia efectiva de los asentamientos existentes por instrumento normativo, siempre rubricado por la intervención de la Comunidad Autónoma. Así, dicha constancia podrá efectuarse por instrumento de planeamiento general (PGOU), y en su defecto, por el Avance a que hace referencia el artículo 4 del Decreto 2/2012.

La inquietud doctrinal respecto a este precepto, se sustancia en el carácter condicionado que para las entidades locales pueda suponer a la hora de declarar las edificaciones en situación de asimilación a la fuera de ordenación. Estas, según el apartado segundo del precepto, están obligadas a reaccionar, ante la ausencia del PGOU, con la elaboración de un Avance de planeamiento para permitir a los afectados solicitar su declaración administrativa. Ello conllevaría apa-

37 La resolución corresponde al Alcalde en función de su competencia reflejada en al art. 23.1. s) de la LRBRL para municipios de régimen común y art. 124.4.ñ) de la LRBRL para Municipios de Gran Población. 
rejado un arduo procedimiento administrativo que, independientemente a la temporalidad fruto de trámites como la información pública o la solicitud de informes a la Consejería competente entre otros, mantendría en suspenso las solicitudes de los interesados respecto a la declaración de asimilación de sus edificaciones, con consecuencias irreparables.

La justificación de la intervención autonómica en estos procedimientos de reconocimiento y regularización, estriba en el hecho de que son creación de la propia normativa autonómica, y no son atributivas de competencia a los municipios, ya que son consecuencia, precisamente, del incumplimiento de éstos al no ejercitar de forma eficiente las medidas de restablecimiento de la legalidad urbanística.

En cuanto a la resolución, ésta debe contener ciertos contenidos tasados ${ }^{38}$ en la norma disponiéndose de un plazo de seis meses para la resolución y notificación de la misma. En mi opinión, y respecto a la aplicación del silencio negativo por el transcurso del plazo descrito, cabría plantearse la existencia de un supuesto viciado de inseguridad jurídica que debe ser solucionado. Constituye ésta una de las consecuencias irreparables a las que antes hice referencia, por cuanto la imposibilidad de medios propios de muchas Entidades Locales pequeñas y medianas para elaborar la delimitación en el PGOU de los asentamientos urbanísticos, supone un lastre importante respecto a las declaraciones solicitadas. En resumen, el hecho de que sea una figura definida por exclusión y cuyo procedimiento pueda resolverse desestimatoriamente por motivos de silencio, otorga una gran discrecionalidad al órgano municipal a la hora de regularizar estas edificaciones, calificándose de continuista el régimen jurídico aplicable a los mismos.

Según lo indicado por el Prof. MELLADO RUIZ, y en disconformidad con la literalidad aparente del art. 53.4 del RDUA, la resolución declarativa del transcurso del plazo previsto para la adopción del procedimiento de legalidad urbanística, no debe servir para determinar la declaración de situación de asimilación a fuera de ordenación según se desprende del mismo, sino que son dos procedimientos distintos, derivados de dos resoluciones diferentes.

Especial mención requiere el régimen excepcional de aquellas viviendas existentes que son constitutivas de la condición de residencia habitual de sus propie-

38 Deberá pronunciarse sobre la identificación de la edificación, el reconocimiento de su idoneidad para el uso al que fue destinado, el otorgamiento o denegación de la situación de asimilación a fuera de ordenación, y la especificación de las obras autorizadas y servicios básicos a que pueden acceder por suministro de compañías suministradoras. 
tarios. Así, la Disposición Transitoria Tercera de la Ley 2/2012, de 30 de enero, otorga la posibilidad de que los municipios autoricen, sólo en estos casos y de manera temporal, la contratación de los servicios básicos con las compañías suministradoras hasta que sea resuelto el procedimiento de reconocimiento y "regularización" de este tipo de edificaciones. Para ello, el Ayuntamiento debe certificar, por medio de informes técnicos y jurídicos, la terminación efectiva de la edificación y el uso real como residencia habitual de sus propietarios, siempre, como es lógico, sin perjuicio de la existencia de procedimiento judicial en curso o la posible inducción a la implantación de nuevas edificaciones fruto de la necesidad de obras precisas para realizar las acometidas por compañías suministradoras.

Ahora bien, esta existencia de servicios autorizados no se traduce en una legalización de actuaciones ni deriva en una transformación del suelo en urbano (STS de 6 de octubre de 1999). La propia Jurisprudencia en STS de 6 de mayo de 1997, determinó que, en los supuestos de ilegalidades urbanísticas, la transformación en la clasificación del suelo como consecuencia de la fuerza de los hechos, supondría un resultado jurídico inadmisible.

No me gustaría acabar sin hacer referencia, y según opinión doctrinal del Prof. SÁNCHEZ SÁEZ, sobre una de las garantías esenciales de los administrados en materia de urbanismo como es la posibilidad de legalizar edificaciones sin licencia que no incumplan la ordenación urbanística. Partiendo de la base del hecho de que sería aplicable la normativa en el momento de la legalización de estas obras, la LOUA, la doctrina y la jurisprudencia del TS, determinan que deben ser susceptibles de convalidación o legalización (expresa o por silencio administrativo positivo). Para ello se seguirán los trámites propios de las solicitudes de licencias de obras u órdenes de ejecución, independientemente de la incoación de expediente sancionador correspondiente. Por tanto, la normativa urbanística aplicable para la legalización es la vigente en el momento del otorgamiento, si el procedimiento se resolvió expresamente dentro del plazo máximo establecido para ello, y la vigente en el momento de su solicitud, si la resolución expresa fue extemporánea.

No obstante, cabe que se produzca una excepción, ya que según el resquicio que abre el art. 182.3 de la LOUA, permite que de forma excepcional y en aplicación al principio de proporcionalidad, sea posible legalizar con disconformidades no sustanciales con la ordenación urbanística aplicable, por resultar de imposible o muy difícil reposición...

\section{De la reclasificación de los suelos como última solución.}

Como vía alternativa a la declaración de asimilación a fuera de ordenación, nos encontramos con la posibilidad de que, por medio de revisión de planea- 
miento general, se reclasifique el suelo convirtiéndolo en urbano. Esta opción viene sustentada Jurisprudencialmente por STS de 1 de octubre de 2009, donde se sostiene:

"que las urbanizaciones ilegales pueden ser clasificadas por el planeamiento general como suelo urbano a desarrollar mediante plan especial de reforma interior, con la consiguiente obligación de los propietarios de urbanizar y hacer las cesiones referidas por el plan".

Con ello, se salvaguarda la obligación de obtener licencia de primera ocupación en relación a la contratación de los servicios básicos generales, debido a que, de acuerdo con el art. 26 del RDUA, no era susceptible de concesión en aquellas obras declaradas ilegales.

Esta vía de regularización, ya se entiende planteada, de forma indirecta, por el propio RDUA, cuando en su art. 53.3 establece que la posibilidad de declaración en situación de asimilado se entiende sin perjuicio de lo que se acordare en el correspondiente instrumento de planeamiento general respecto del desarrollo, ordenación y destino de las obras, instalaciones, construcciones o edificaciones afectadas por la declaración de asimilación o la situación de fuera de ordenación”.

El Decreto 2/2012, también recoge indirectamente esta vía de reclasificación de los suelos cuando hace referencia a la "integración" fundamentalmente de los asentamientos en suelo no urbanizable. En estos casos, serán los propietarios los encargados de asumir los costes de urbanización, cargas y deberes urbanísticos correspondientes.

\section{GONGLUSIONES}

1. La situación legal de fuera de ordenación es aquella institución urbanística que, nacida con arreglo a la ordenación urbanística, deviene disconforme a consecuencia de la sucesión de normas en el tiempo y del "ius variandi" del planificador. Fue introducida por nuestra Ley de Suelo de 1956 con el propósito de establecer un equilibrio entre los intereses privados, derivados de los derechos subjetivos consolidados, y los públicos, precursores del cumplimiento de la normativa urbanística, territorial y ambiental. El sistema de fuera de ordenación viene configurado por los instrumentos de planeamiento, los cuales se encargan de establecer el régimen jurídico aplicable a estas edificaciones existentes, donde será la Administración pública la encargada de otorgar las facultades del propietario, delimitando, en consecuencia, el contenido de un derecho de propiedad que pasa de ser dominical a estatutario. Éste régimen distinto se caracteriza por la restricción de las obras realizables a estas edificaciones y construcciones desordena- 
das, provocando su demolición por agotamiento y posterior declaración de ruina urbanística del inmueble con su desaparición. El régimen legal de la situación de fuera de ordenación, ha sido objeto de una regulación jurídica evolutiva en la Comunidad Autónoma de Andalucía, mediante la Ley 7/2002 de Ordenación Urbanística de Andalucía (LOUA), regulado en su art. 34 b) y en su Disposición Adicional Primera, y posteriormente, con el primer Reglamento de desarrollo urbanístico andaluz, por Decreto 60/2010 por el que se aprueba el Reglamento de Disciplina Urbanística de Andalucía (RDUA).

2. Junto a esta figura, el RDUA concede carta de naturaleza a la que vino a calificar como "situación de asimilación a la de fuera de ordenación" (art. 53 RDUA). Esta nueva figura viene caracterizada, no sólo por su disconformidad con la ordenación urbanística vigente, sino porque ya en su origen eran construcciones clandestinas e ilegales, quedando impunes a efectos jurídicos por el mero hecho del transcurso del plazo para ejercer la potestad de restablecimiento de la legalidad urbanística. Su acertada regulación, sin que suponga un reconocimiento legal de tal situación de incompatibilidad urbanística, atiende a la necesidad de rescatar esta figura del limbo jurídico donde se encontraba, para dotarla de una situación jurídica específica fruto de la actividad administrativa. En relación a la regulación desarrollada por el RDUA, donde se acuña esta institución como una figura "asimilada" a la "situación legal de fuera de ordenación", parece cuanto menos incomprensible debido a que se establece, a priori, un régimen jurídico más laxo y tolerante con estas edificaciones, construcciones e instalaciones que son ilegales desde el momento de su nacimiento.

3. Es importante especificar, que esta figura de "asimilación a la de fuera de ordenación" no es una novedad jurídica regulada por el RDUA, sino que trae consecuencia de la jurisprudencia del Tribunal Supremo. Así en las SSTS de 5 de diciembre de 1987, de 8 de noviembre de 1990, de 6 de febrero de 1991 y de 19 de mayo de 1992, ya conceptuaba de "situación análoga a la de fuera de ordenación", a aquellas obras ilegales en las que el plazo para la restauración de la legalidad urbanística había transcurrido. Si bien esas obras no pueden ser legalizadas, según indica el Tribunal Supremo, "por cuanto nacieron de una situación de ilegalidad, haciéndolas diferentes de aquellas realizadas conforme a la ordenación urbanística, pero que devinieron ilegales por la alteración del planeamiento, las cuales quedarían en situación análoga a la fuera de ordenación". En resumen, el Tribunal Supremo con esta jurisprudencia hace necesaria la armonización de la permanencia y utilización de este tipo de edificaciones con la prohibición de acometer obras que alarguen la vida de las mismas.

4. Cabe destacar, en virtud del principio de igualdad, el diferente tratamiento existente entre los supuestos de fuera de ordenación, que nacidos de una si- 
tuación legal, devienen ilegales por cambio de planeamiento, de los supuestos de "asimilación", donde, nacida de la ilegalidad urbanística, la restitución del bien jurídico perturbado queda exenta de demolición por el mero transcurso del tiempo. Así, este necesario tratamiento desigual se traduce en una distinta valoración de las edificaciones en eventuales procedimientos expropiatorios, así como en un régimen diferente de obras y actuaciones admisibles, por cuanto en las situaciones de asimilación, únicamente se permiten las obras de reparación y conservación que exija el estricto mantenimiento de las condiciones de seguridad, habitabilidad y salubridad del inmueble, sin permitirse ya las obras parciales y circunstanciales de consolidación. En relación a la publicidad registral, resulta obligatorio para las edificaciones en situación de asimilación, el necesario reflejo de las limitaciones que dicho régimen comporta, debiendo aportarse la resolución finalizadora del procedimiento, plasmando textualmente las condiciones a que se someten las mismas. Una dificultad añadida supone el régimen de acceso a los suministros, sobre todo cuando nos encontramos con la imposibilidad, por parte de las edificaciones declaradas en situación de asimilación, de ser susceptibles de concesión de licencias de ocupación (según aclara definitivamente el Decreto 2/2012), por cuanto debemos insistir en la excepcionalidad, siempre y cuando se produzcan los requisitos fácticos y jurídicos, de la autorización para la acometida a los servicios básicos junto al cumplimiento de determinados requisitos que tendrán que ser constatados con sus informes preceptivos. Conviene reseñar la cuestión polémica derivada de la obligación de contribuir al sostenimiento de los gastos públicos de aquellos que contraviniendo la normativa vigente al tiempo de acometer la edificación, no efectuaron los tributos correspondientes. A este respecto, y abogando a una perfecta aplicación del Decreto 2/2012, debemos exigir a los responsables de las entidades locales que entre las medidas de reconocimiento y reconducción de este tipo de edificaciones no se muestren imprecisos respecto a las cargas exigibles. Algunos autores GALLEGO ALCALÁ, van más allá y defienden la aprobación de nueva normativa aludiendo expresamente a la obligación de los propietarios de prestar una garantía y una prestación compensatoria análogas a las previstas en el artículo 52.4 y 5 de la LOUA.

5. El Decreto 2/2012, aprobado en Consejo de Gobierno Andaluz en 10 de enero de 2012, por el que se regula el régimen de las edificaciones y asentamientos existentes en suelo no urbanizable en la comunidad autónoma de Andalucía, tiene por objeto la regulación jurídica de estas edificaciones, dotando de seguridad jurídica a los titulares de las mismas y a los futuros adquirentes de buena fe. El status jurídico de estas edificaciones se completaría con la posibilidad que se concede a estos sujetos, del pleno conocimiento tanto en el ámbito administrativo como en el hipotecario (Registro de la Propiedad). Así estaríamos, no en una situación de "amnistía" o "regularización generalizada", según multitud de opiniones opositoras manifestadas en los medios de comunicación, sino en 
presencia de una regulación jurídica de edificaciones aisladas o agrupadas en asentamientos urbanísticos o hábitat rural diseminado, a las que se dota de un régimen jurídico en función de su conformidad o disconformidad con la legislación urbanística vigente. Así, el Decreto no vendría a dar una solución sustantiva o material directa, entre otras cosas porque estamos ante una materia sin cobertura legal específica, pero sí el establecimiento del cauce procedimental de "regularización" de las edificaciones asimiladas a fuera de ordenación.

6. Debemos valorar positivamente lo regulado por el Decreto, puesto que, lejos de justificar una "regularización o legalización" de edificaciones existentes en suelo no urbanizable fruto de infracciones urbanísticas, representa una solución a un problema social, económico y medioambiental surgido durante décadas que había que regular en aras al interés general. Acudiendo, para definir esta nueva situación, a las categorías de los sistemas jurídicos, hemos de reconocer que nos encontrábamos ante un problema, más de efectividad, producido por el gran incumplimiento de la norma, que de validez; más de incompetencia que de desregulación normativa; y más de honestidad colectiva que de técnica jurídica. En consecuencia cabe justificar y reforzar el valor de los Cuerpos de Inspectores de Ordenación del Territorio, cuyo principal cometido radica en la defensa y protección de la legalidad urbanística frente al abuso que suponen las apropiaciones ilegales de suelo de algunos sujetos. No obstante, y en disconformidad con la opinión de calificar esta regulación urbanística (que establece el Decreto 2/2012) de continuista cuya estructura es "reglamentista" y "atomizada", si defiendo la proposición de elaborar una normativa reguladora del suelo no urbanizable de forma global e incorporada en un solo texto legal.

7. Respecto al régimen jurídico reconocido a las edificaciones reseñadas como consecuencia de este Decreto, debemos destacar la posibilidad de formular la correspondiente declaración de obra nueva de las edificaciones y su inscripción en el Registro de la Propiedad, previa obtención de las preceptivas autorizaciones administrativas habilitantes como son la licencia de primera ocupación (para edificaciones conformes con el ordenamiento), certificación del estado legal de fuera de ordenación (para las declaradas en situación legal de fuera de ordenación por la LOUA) y la resolución administrativa de reconocimiento en régimen asimilado al de fuera de ordenación (para las recogidas en dicho régimen regulados por el RDUA). En el asiento de inscripción registral, deberá constar el régimen jurídico aplicable y las limitaciones existentes a la situación legal de las edificaciones. Dicho régimen jurídico aplicable, al no estar regulado por el Decreto, será el previsto por el RDUA, en desarrollo del art. 52 de la LOUA.

8. Si puede suponer una contradicción, en la regulación de este Decreto, el hecho de que en la figura de las construcciones asimiladas al régimen de fuera de 
ordenación, se pueda seguir ejerciendo el uso y disfrute de dichas construcciones (aunque por medio de un complejo procedimiento administrativo donde el ayuntamiento debe certificar la seguridad y las instalaciones para ejercer el uso y disfrute), pero la resolución de dicho procedimiento no suponga nunca la concesión de primera ocupación, ni tampoco suponga derecho alguno al propietario ante cualquier procedimiento administrativo o penal que se pueda ejercitar (art. 8.6 del Decreto). A su vez, otro problema derivado de la creación de la figura de "asimilado al régimen de fuera de ordenación" por el RDUA, lo encontramos en el hecho de que la legislación estatal debería incluirla en su legislación a efectos de poder inscribir en el Registro de la Propiedad cualquier acto administrativo que establezca una construcción como asimilada a régimen de fuera de ordenación, ya que las competencias del Registro de la Propiedad son de carácter estatal y no autonómico.

9. No obstante, y haciendo unas críticas constructivas a lo regulado por el Decreto, opino que:

- como consecuencia de una normativa motorizada, y frente a la importancia del problema sustantivo que esta situación requiere, no se han abordado ciertas cuestiones de contenido, provocando cierta inseguridad jurídica en las soluciones adoptadas. Por ello, parece estar enfocada más a criterios de oportunidad político-administrativas, que a solucionar los conflictos entre los intereses particulares y generales.

- el Decreto, se extralimita en su función de desarrollo de la normativa legal vigente, por cuanto mantiene la ampliación a dos de los supuestos de fuera de ordenación recogidos en su día por el RDUA (incluyendo el "cumplimiento por equivalencia") respecto de lo contemplado en la D.A. ${ }^{a}$ de la LOUA. Además, respecto al contenido del régimen jurídico aplicable a los inmuebles declarados en situación de asimilación a la de fuera de ordenación, otorga un contenido "innovador" a la declaración de reconocimiento de tal situación por parte del Ayuntamiento, cuando dicha resolución debería ser meramente declarativa de una realidad fáctica sobrevenida. De igual forma, y en relación al suministro de los servicios básicos, la mera declaración administrativa de reconocimiento de la situación de asimilación a la de fuera de ordenación, no debería ser constitutiva de título jurídico habilitante para el acceso a dichos suministros, provocando la equiparación, con esta concesión, con las licencias de primera ocupación o utilización, por el contrario vetadas para este tipo de edificaciones. A su vez, parece chocante que el propio Ayuntamiento, sujeto sobre el que recae la potestad de disciplina urbanística, pase a ser también 
el órgano competente para reconocer la regularización de la situación fáctica de las edificaciones ilegales.

- por lo que al régimen transitorio se refiere, la ampliación del plazo para adoptar las medidas de restitución de la realidad física alterada a seis años, no hace más que dar un mayor margen de maniobra a los Ayuntamientos, pero no aporta soluciones de carácter sustantivo, provocando la pervivencia del problema de las viviendas ilegales.

10. Para finalizar, considero que el Decreto, si bien ayuda a clarificar determinadas cuestiones imprecisas, ha perdido la oportunidad de regular, de forma sustantiva, cuestiones tan importantes para combatir la indisciplina urbanística, como:

- el refuerzo de las facultades de control urbanístico de los Ayuntamientos, abriendo la puerta a la actuación de la administración autonómica por causas de incumplimiento.

- la ampliación de los criterios intervencionistas, actuando cautelarmente para evitar la proliferación de la ocupación ilegal del suelo. -la dotación de medios materiales y personales para la consecución de tal fin...

\section{BIBLIOGRAFÍA}

ARANA GARCÍA Y TORRES LÓPEZ (coordinadores), "La Disciplina Urbanística en Andalucía", Tirant lo Blanc, 2011.

ARIÑO SÁNCHEZ, Rafael, "Edificios fuera de ordenación en la Jurisprudencia (1985-1999)", Revista de derecho urbanístico y medio ambiente, Año n ${ }^{\circ} 34$, No 181, 2000, págs. 11-48.

BAÑO LEÓN, José María, Derecho Urbanístico Común, Iustel, 2009.

BOPA, Proyecto de Ley de modificación de la Ley 7/2002, de 17 de diciembre, de Ordenación Urbanística de Andalucía, No 781, 2011.

CAMY ESCOBAR, Jesús, Y DELGADO RAMOS, Joaquín, "Cuestiones de derecho transitorio relacionadas con la declaración de edificaciones asimiladas a fuera de ordenación en Andalucía", Aletheia: Cuadernos Críticos del Derecho, $\mathrm{N}^{\circ}$ 2, 2012, págs. 46-55. 
CARBALLEIRA RIVERA, María Teresa, "Edificios fuera de ordenación y obras permitidas", Revista de derecho urbanístico y medio ambiente, Año no 38, No 214, 2004, págs. 11-44.

CORTÉS MORENO, Álvaro, "El régimen jurídico de la situación legal de fuera de ordenación. La declaración de asimilación a la de fuera de ordenación en el derecho urbanístico andaluz", La Ley: Práctica Urbanística, N 109, 2011.

FERNÁNDEZ CARBALLAL, Almudena, "El régimen jurídico del urbanismo en España. Una perspectiva competencial”, Madrid, 2001.

GAMERO RUÍZ, Eva, "Aspectos técnicos y jurídicos de la situación de asimilación a la de fuera de ordenación en Andalucía". I Jornadas de la Asociación de Inspectores de Ordenación del Territorio, Urbanismo y Vivienda de la Junta de Andalucía, Sevilla, 16 y 17 de abril de 2012.

GALLEGO ALCALÁ, José Domingo, "Breve aproximación al artículo 53 del Reglamento de Disciplina Urbanística de Andalucía: Situación asimilación a fuera de ordenación", Consultor de los ayuntamientos y de los juzgados: Revista técnica especializada en administración local y justicia municipal, $\mathrm{N}^{\mathrm{o}} 13$, 2011, págs. 1646-1661.

GALLEGO ALCALÁ, José Domingo, "Aplicación práctica del Decreto 2/2012, de 10 de enero, de la Junta de Andalucía desde el prisma de un operador jurídico local, con especial incidencia en las edificaciones aisladas y la declaración de situación de asimilación a fuera de ordenación". Consultor de los ayuntamientos y de los juzgados: Revista técnica especializada en administración local y justicia municipal, $\mathrm{N}^{\circ}$ 5, 2013, págs. 525-537.

GARCÍA GARRO, Ma Aránzazu, "Alcance de la situación de fuera de ordenación”, Revista Aranzadi de Urbanismo y Edificación, No 27, 2013, págs. 153174.

GUTIÉRREZ COLOMINA, Venancio, "La modificación de la LOUA y el régimen jurídico de las edificaciones y asentamientos urbanísticos existentes en el suelo no urbanizable", Revista de Derecho Urbanístico y Medio Ambiente, $\mathrm{N}^{\mathrm{o}} 272$, 2012, págs. 129-206.

JORDANO FRAGA, Jesús, "Efecto directo horizontal de determinadas Directivas Ambientales: la consagración jurisprudencial de la invocabilidad por par- 
ticulares de las directivas en relaciones triangulares (comentario a la Sentencia del Tribunal de Justicia (Sala Quinta) de 7 de enero de 2004 en el asunto c-201/02)". Revista electrónica Medio ambiente y Derecho.

JORDANO FRAGA, Jesús, "La Reclasificación del Suelo No Urbanizable”, Revista Aranzadi de Urbanismo y Edificación, No 21, 2009.

LÓPEZ MENUDO, Francisco (coordinador), "Derechos y Garantías del Ciudadano: Estudios en homenaje al Profesor Alfonso Pérez Moreno", Iustel, 2011.

LÓPEZ RAMÓN, Fernando, "Introducción al Derecho Urbanístico ( $3^{a}$ edic)", Marcial Pons, 2009.

MELLADO RUIZ, Lorenzo, "Reflexiones críticas cobre el nuevo régimen andaluz de las edificaciones y asentamientos en suelo no urbanizable: el problema de las viviendas "alegales"”, Práctica Urbanística: Revista mensual de urbanismo, $\mathrm{N}^{\mathrm{o}} 117,2012$, págs. 30-45.

PEÑARANDA RAMOS, José Luis, "La ordenación urbanística: planeamiento, ejecución y protección de la legalidad", 2011.

RAMÓN FERNANDEZ, Tomás, "Manual de Derecho Urbanístico, 22ª edic". La Ley, Consultor de los ayuntamientos, 2011.

RAMOS MEDRANO, María Paz y José Antonio, "La pretendida deslegalización del régimen jurídico de fuera de ordenación", Revista de derecho urbanístico y medio ambiente, Año no 30, Nº 148, 1996, págs. 103-114.

REBOLLO PUIG, Manuel, "Derecho Urbanístico y Ordenación del Territorio en Andalucía", Iustel, 2007.

SÁNCHEZ SÁEZ, Antonio José, "Tres garantías esenciales de los administrados en materia de urbanismo: la posibilidad de legalizar edificaciones sin licencia que no incumplan la ordenación urbanística", Estudios en homenaje al profesor Alfonso Pérez moreno, Iustel, 2011, págs. 1.005-1.051.

VVAA, Memento Práctico Francis Leffebvre, Urbanismo 2012.

"Constancia registral de la situación de fuera de ordenación de parte de un edificio", Consultor de los ayuntamientos y de los juzgados: Revista técnica especializada en administración local y justicia municipal, $\mathrm{N}^{\circ} 18,2009$, pág. 2595. 
"Derecho al empadronamiento en vivienda en situación de fuera de ordenación", Consultor de los ayuntamientos y de los juzgados: Revista técnica especializada en administración local y justicia municipal, $\mathrm{N}^{\circ}$ 6, 2010, págs. 864-865.

"Obras en edificaciones en situación de fuera de ordenación. Sentido del silencio administrativo", Consultor de los ayuntamientos y de los juzgados: Revista técnica especializada en administración local y justicia municipal, $\mathrm{N}^{\circ} 24$, 2012, págs. 2739-2741.

"Posibilidad de concesión de licencia de apertura para uso en edificio fuera de ordenación", Consultor de los ayuntamientos y de los juzgados: Revista técnica especializada en administración local y justicia municipal, $\mathrm{N}^{\circ} 18$, 2011, págs. 2123-2124.

"Posible expropiación de una edificación declarada "fuera de ordenación" que ofrece peligros y puede atentar contra la seguridad", Consultor de los ayuntamientos y de los juzgados: Revista técnica especializada en administración local y justicia municipal, $\mathrm{N}^{\circ}$ 9, 2009, págs. 1285-1286. 